\title{
La inteligencia artificial aplicada a la robótica en los conflictos armados. Debates sobre los sistemas de armas letales autónomas y la (in)suficiencia de los estándares del derecho internacional humanitario
}

\author{
Artificial Intelligence Applied to Robotics in Armed Conflict. \\ Debates on Autonomous Lethal Weapons Systems and the \\ (In)Sufficiency of the Protocols of International Humanitarian Law \\ A inteligência artificial aplicada à robótica nos conflitos armados. \\ Debates sobre os sistemas de armas letais autônomas e a \\ (in)suficiência dos standards do direito internacional humanitário
}

\author{
Adriana Margarita PorCELLI
}

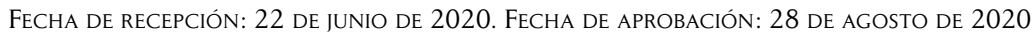

Doi: https://doi.org/10.12804/revistas.urosario.edu.co/sociojuridicos/a.9269

Para citar este artículo: Porcelli, A. M. (2021). La inteligencia artificial aplicada a la robótica en los conflictos armados. Debates sobre los sistemas de armas letales autónomas y la (in)suficiencia de los estándares del derecho internacional humanitario. Revista de Estudios Socio-Jurídicos, 23(1), 483-530. https://doi.org/10.12804/revistas. urosario.edu.co/sociojuridicos/a.9269

\section{RESUMEN}

El presente artículo de revisión se centra en el potencial uso de las armas autónomas letales, denominadas por el premio Nobel Jody Williams como robots asesinos, en los conflictos armados y analiza su principal problemática: la aptitud de tales armas para cumplir con el derecho internacional humanitario y de los derechos humanos o la necesidad de dictar un marco jurídico y ético regulatorio que prohíba preventivamente su implementación. Para ello se utilizó el método científico, específicamente, la investigación bibliográfica referida a los avances informáticos militares y al relevamiento de la legislación internacional en la temática. Se trata de un estudio de tipo

* Abogada (Universidad de Buenos Aires) Magister en Relaciones Internacionales (Universidad Maimónides) Diploma en Derechos Económicos Sociales y Culturales (Universidad Nacional de la Patagonia San Juan Bosco) Investigadora y Profesora Adjunta Ordinaria, Departamento de Ciencias Sociales (Universidad Nacional de Luján). Argentina. Correo electrónico: adporcelli@yahoo.com.ar. ORCID: https://orcid.org/0000-0002-5192-5893 
bibliográfico-documental descriptivo, que recolecta datos publicados en revistas y libros especializados en derecho internacional humanitario y en defensa y estrategia militar de diferentes países. Una de las conclusiones a las que permitió llegar el trabajo es que en la actualidad no existe un consenso normativo ni conceptual, a nivel internacional, para la aplicación de los sistemas de armas autónomas y que la prohibición preventiva no es la respuesta al problema.

Palabras clave: inteligencia artificial; robótica; sistemas de armas; automatización; derecho humanitario internacional.

\section{ABSTRACT}

This review article focuses on the potential use of lethal autonomous weapons, called by the Nobel laureate Jody Williams, killer robots in armed conflicts, and analyzes its main problem: the aptitude of such weapons to comply with the international humanitarian law and human rights or the necessity to dictate a legal and ethical regulatory framework that preventively prohibits their implementation. The methodology used was based on the scientific method, specifically on bibliographic research related to military computer advances and the survey of international legislation on the subject. It is a bibliographic-documentary and descriptive study in which data published in journals and specialized books on international humanitarian law and on defense and military strategy from different countries were collected. One of the conclusions is that currently there is no normative or conceptual consensus at the international level in the application of autonomous weapons systems and that preventive prohibition is not the conclusive answer to the problem.

Keywords: Artificial intelligence; robotics; weapons systems; automation; international humanitarian law.

\section{RESUMO}

O presente artigo de revisão centra-se no potencial uso das armas autônomas letais, denominadas pelo prémio Nobel Jody Williams, robôs assassinos nos conflitos armados e analisa sua principal problemática consistente na aptidão de tais armas para cumprir com o Direito Internacional Humanitário e dos Direitos Humanos, ou pelo contrário, é necessário o ditado de um marco jurídico e ético regulatório que proíba preventivamente a sua implementação. A metodologia utilizada baseou-se no método científico, especificamente na pesquisa bibliográfica referida aos avanços informáticos militares e ao relevamento da legislação internacional na temática. Trata-se de um estudo de tipo bibliográfico-documental e descritivo no qual se coletaram os dados publicados em revistas e livros especializados em Direito Internacional Humanitário e em defesa e estratégia militar de diferentes países. Uma das conclusões obtidas é que na atualidade não existe um consenso normativo nem conceitual no nível internacional na aplicação dos sistemas de armas autônomas e que a proibição preventiva não é a resposta concluinte ao problema.

Palavras-chave: inteligência artificial; robótica; sistemas de armas; automatização; direito humanitário internacional. 


\section{Introducción}

El desarrollo de la inteligencia artificial (IA) y la robótica avanza de manera exponencial y a un ritmo inimaginable. Hasta hace unos años, los robots eran parte de la literatura de ciencia ficción. Sin embargo, hoy en día conviven con los seres humanos, colaborando en las más variadas tareas, impactando tanto en el mercado laboral como todas las demás esferas de la sociedad. Es más, los profesores Erik Brynjolfsson y Andrew McAfee (2014), del Massachusetts Institute of Technology (MIT), estimaron que el mundo se encuentra frente a un punto de inflexión sin precedentes producido por la automatización, que calificaron como "la segunda era de las máquinas". En concreto, estas pueden ayudar con tareas del hogar o realizar actividades que los individuos nunca hubieran podido concretar bien porque afectan la integridad del investigador o por falta de tecnología. Por ejemplo, en la exploración del espacio exterior y en la minería cabe resaltar ventajas como la seguridad en la excavación y la extracción de combustible.

A modo indicativo, se pueden mencionar los siguientes robots con inteligencia artificial más representativos del desarrollo tecnológico de los últimos años: los robots humanoides Asimo de Honda, Pepper o Sanbot, cuyo propósito es ser compañeros emocionales del propietario -son capaces de hablar y entender las emociones humanas o incluso de expresar algunas de ellas-y Sophia, mundialmente famosa por convertirse en la primera robot en adquirir una nacionalidad, la saudita.

Además, están la pelota Ballie, un asistente inteligente desarrollado por Samsung que posee movilidad autónoma y controla todos los sistemas que integran un hogar inteligente desde abrir o cerrar las cortinas hasta encender el televisor y vigilar la casa, Atlas, creado para participar en operaciones de rescate o búsqueda -dotado de una fuerza impresionante y con capacidad de tomar decisiones-, y RHex que puede escalar y funcionar hasta en los terrenos más difíciles y en zonas de acceso imposibles para humanos. Por último, se pueden mencionar los robots industriales, algunos son grandes brazos robóticos que levantan piezas enormes de materiales pesados como el acero (Riquelme, 2020), mientras que otros pueden no tener ninguna forma visible como en las aplicaciones Siri de Apple, Alexa de Amazon, Cortana de Microsoft 
y Google Now de Google. Estos productos son auténticos cerebros globales porque utilizan contenidos disponibles en Internet y no están sujetos a las limitaciones de sus diseñadores (Barrio Andrés, 2018b).

Los ejemplos citados, así como las innumerables aplicaciones posibles, muestran la utilización de los robots en beneficio de la humanidad, centrados en la persona natural. Sin embargo, también hay un fuerte impulso en su desarrollo para el campo bélico. Tanto es así que la organización no gubernamental Pax, entre otras, advierte sobre la peligrosidad de una nueva carrera armamentística entre Estados Unidos y China.

Esta última situación es la que articula el presente artículo de revisión, ${ }^{1}$ cuyo tema es el potencial uso de las armas autónomas letales, denominadas por el premio Nobel Jody Williams como robots asesinos en los conflictos armados. Se analizará su principal problemática: la aptitud de tales armas para cumplir con los principios del derecho internacional humanitario y del derecho internacional de los derechos humanos o si es necesario dictar un marco jurídico y ético regulatorio que prohíba preventivamente su implementación.

En virtud de lo expuesto, el trabajo parte de la siguiente pregunta: ¿es suficiente y pertinente la legislación internacional humanitaria vigente en materia de conflictos armados o es necesario dictar un marco jurídico y ético específico para la implementación de armas autónomas letales? Para responder a este interrogante, el artículo analizará los principios del derecho internacional humanitario frente a los sistemas de armas letales autónomas. Para ello se consultaron fuentes primarias - normativa internacional vigente - y secundarias - estudios jurídicos y tecnológicos para la comprensión del funcionamiento de los sistemas inteligentes, en defensa y estrategia militar en diferentes países (especialmente las investigaciones realizadas en el Instituto Español de Estudios Estratégicos, el Centro de Investigaciones y Estudios Estratégicos de Chile, el Ministerio de Defensa de los Estados Unidos y el Sistema de Biblioteca Digital de las Naciones Unidas) -. También se realizó un relevamiento, a modo de ejemplo, de los principales sistemas de armas inteligentes

1 La metodología utilizada fue el método científico, específicamente, la investigación bibliográfica referida a los avances informáticos militares y al relevamiento de la legislación internacional en la temática. Se trata de un estudio de tipo bibliográfico-documental descriptivo. 
existentes en la actualidad y se consultaron los resultados vertidos en el libro Robótica, armas y derecho internacional del equipo de investigación dirigido por Juan Ramón Martínez Vargas, integrado por Andrés Felipe López Latorre, Steffany Serebreni Beltrán y Natalia Fernández Alba.

Entre los expertos juristas, científicos y filósofos que estudiaron el posible cumplimiento o incumplimiento de las normas del ius ad bellum por parte de los sistemas de armas autónomos estudiados, se destacan: Christof Heyns (2013)- Relator Especial del Consejo de Derechos Humanos, Ronald Arkin (2009), Roser Martínez Quirante y Joaquín Rodríguez Álvarez (2018), Carlos Fernando Álvarez González (2017), Noel Sharkey (2012), Martha Isabel Hurtado Granada (2017), Juan Ramón Martínez Vargas, Andrés Felipe López Latorre, Steffany Serebreni Beltrán y Natalia Fernández Alba (2019), Peter Bergen (2014), Gómez de Águeda (2019), Toby Walsh (2020), Stuart Russell, Elon Musk, Stephen Hawking, Noam Chomsky y Peter Norving (2015).

Además, se tuvo en cuenta la posición de las organizaciones internacionales no gubernamentales que participan activamente en Naciones Unidas para lograr su prohibición preventiva: el Comité Internacional de la Cruz Roja, Amnistía Internacional, International Human Rights Clinic y la Campaign to Stop Killer Robots que representa a setenta organizaciones en treinta países, en particular PAX, Human Rights Watch, Article 36.

Con los datos recolectados acerca de la implementación de los sistemas autónomos en los conflictos armados y del análisis normativo, se realizó un balance de los mismos. Una de las conclusiones es que, en la actualidad, no existe un consenso normativo ni conceptual a nivel internacional en la aplicación de los sistemas de armas autónomas y que la prohibición preventiva no es la respuesta al problema.

El trabajo se compone de tres partes. La primera desarrolla el marco conceptual, en el que se definen la IA y la robótica para comprender su aplicación en el actual contexto bélico. La segunda describe los avances en armas autónomas, su peligrosidad desde la mirada tanto de sus defensores como de sus detractores, y analiza la suficiencia y la adecuabilidad de la legislación internacional vigente o si es necesario dictar un nuevo marco jurídico y ético. La tercera tiene como finalidad presentar la guerra a futuro y controlada por redes, en la cual los proveedores 
de internet, los motores de búsqueda y el geoposicionamiento global pertenecen a multinacionales tecnológicas. Así como el actual doble uso - civil y militar- de las tecnologías disruptivas.

\section{Marco conceptual}

A los efectos de una cabal comprensión del potencial de las armas autónomas, se desarrollarán brevemente los conceptos de IA y robótica, destacando que, si bien ambas son tecnologías disruptivas, no son sinónimos.

\section{Inteligencia artificial}

En primer lugar, se conceptualizará el término inteligencia. Pérez Luño (1996) considera que, en occidente, se pueden diferenciar tres grandes acepciones de dicho vocablo: a) como práctica: virtud para discernir y actuar racionalmente; b) como saber teórico: permite aprehender y representar formalmente la realidad, y c) como racionalidad instrumental: alude a la idoneidad de los medios requeridos para la obtención de determinados objetivos. Para expresar estas últimas dos acepciones, actualmente se distingue entre inteligencia epistemológica, que permite la representación formal del mundo y la solución de los problemas, e inteligencia heurística, que en función de informaciones y conocimientos adquiridos privados resuelve problemas y decide los medios o instrumentos adecuados para el logro de objetivos.

Este mismo autor advierte que la noción de inteligencia, tanto en su sentido epistemológico como heurístico, resulta predicable respecto a determinados tipos de software que reproducen procesos mentales. Sin embargo, no implica que la inteligencia humana pueda ser íntegramente suplantada por las computadoras, ya que existe un sector de la misma, el práctico, en el que la posibilidad de aplicar la IA resulta más problemática. Se trata de actividades y valoraciones que los seres humanos llevan a cabo a través de su estructura biológica y psicológica en función de experiencias sociales y culturales (Pérez Luño, 1996). 
Actualmente, no se ha consensuado en forma universal una única definición para el término IA por la rapidez en que avanza la tecnología. Este fue acuñado en 1956 por el científico John McCarthy, cuando, junto con Minsky, Rochester y Shannon comenzaron, en el Dartmouth College en los Estados Unidos, el proyecto de investigación "Inteligencia artificial". Inicialmente, su objetivo era que la inteligencia humana pudiera ser descrita de forma tan precisa que una máquina fuera capaz de simularla. Este concepto también fue conocido como inteligencia artificial genérica, consistente en la inteligencia artificial igual o superior a la capacidad humana promedio. John McCarthy la definió como

la ciencia y la ingeniería de hacer máquinas inteligentes, especialmente programas informáticos inteligentes. Está relacionado con la tarea similar de usar computadoras para comprender la inteligencia humana, pero la IA no tiene que limitarse a métodos que son biológicamente observables (McCarthy, 2007, p. 1).

También ha sido conceptualizada como "una disciplina informática encargada de realizar programas de computadora, cuyo resultado final (producto de reglas de transformación y composición), de ser imputado a un humano implicaría inteligencia" (Cáceres, 2006, p. 6).

Con el transcurso del tiempo y a medida que los avances tecnológicos fueron perfeccionándose hacia áreas de conocimiento específicos, el concepto de IA fue evolucionando hacia una combinación entre el reconocimiento de imagen, el procesamiento de lenguaje, las redes neuronales y las acciones orientadas a un único objetivo. Por ejemplo, vehículos autónomos, realidad virtual, sanidad, reconocimiento visual, manipulación y análisis de datos, y aparatos domésticos o ciberseguridad.

La Comisión Europea (2018) considera que:

el término «inteligencia artificial» (IA) se aplica a los sistemas que manifiestan un comportamiento inteligente, pues son capaces de analizar su entorno y pasar a la acción -con cierto grado de autonomía- con el fin de alcanzar objetivos específicos. Los sistemas basados en la IA pueden consistir simplemente en un programa informático (p. ej. asistentes de voz, programas de análisis de imágenes, motores 
de búsqueda, sistemas de reconocimiento facial y de voz), pero la IA también puede estar incorporada en dispositivos de hardware (p. ej. robots avanzados, automóviles autónomos, drones o aplicaciones del internet de las cosas) (p.1).

Cuando se menciona la palabra 'inteligente' se incurre en el equívoco que el sistema es capaz de realizar cualquier tarea que un ser humano inteligente puede realizar desde las actividades más simples como ir al supermercado, cocinar y lavar hasta las más complejas como escribir un libro, jugar ajedrez, dictar sentencia o diagnosticar una enfermedad. Nada más alejado de la realidad, ya que la IA es limitada, que sea capaz de resolver un problema particular, no significa que tiene la capacidad de resolver otro diferente.

John Searle (1980) fue el primer autor que diferenció entre dos métodos de inteligencia artificial: débil y fuerte. El primero se centra únicamente en tareas rutinarias y técnicas, solo se aplica a un tipo específico de problemas, que no requieren de la capacidad de pensar. En cambio, el segundo implica que una computadora no simula una mente, sino que es "una mente" y, por consiguiente, tendría una inteligencia igual o incluso superior a la humana. Es decir, tiene capacidad de abstracción, reflexión, habilidades sociales, afán creativo e improvisación, con capacidad de autoprogramación, imitación del comportamiento humano, aprende de las personas tareas nuevas similares a las humanas y posee capacidad de adaptación a nuevos escenarios (Searle, 1980). Actualmente no existen ejemplos de esta última, que solo se ha visto en el campo de la ciencia ficción.

En efecto, los sistemas dotados de inteligencia artificial son capaces de resolver eficazmente una única tarea, una vez contextualizada. Sin embargo, no poseen la habilidad de sumar aprendizajes como los humanos. Por ejemplo, pueden saber jugar muy bien al ajedrez, pero ser incapaces de encontrar un tumor en una imagen; si aprenden a identificar tumores, se olvidarán de la manera de jugar ajedrez. Esto es lo que se conoce como olvido catastrófico. Dicho concepto alude a la dificultad de enseñar nuevas habilidades al sistema para realizar nuevas tareas sin perder las funciones previamente aprendidas. Si una red entrenada inicialmente para distinguir entre fotos de brazos y piernas se 
vuelve a entrenar para distinguir entre brazos y manos, sobre escribirá la información anterior y perderá la capacidad asociada a ella (López de Mántaras, citado por Paniagua, 2019).

Si bien excede el objeto del presente artículo, no se puede explicar la IA sin mencionar los aportes de Noam Chomsky al lenguaje computacional, cuando propuso la gramática generativa, una teoría del lenguaje inspirada en los lenguajes artificiales de la lógica y las matemáticas. Según este prestigioso académico, la facultad para aprender idiomas es parte del organismo. En la mente humana ya existe algo innato que será el germen del lenguaje, por ello, los humanos adquieren un sistema cognitivo lingüístico. De acuerdo con este principio, el lenguaje puede ser transmitido genéticamente y los seres humanos poseen una estructura lingüística similar independientemente de sus diferencias sociales y culturales (Chomsky, 1957).

Así, Chomsky (1957) estableció cuatro tipos de lenguaje con sus correspondientes gramáticas y máquinas asociadas en forma jerárquica: la Jerarquía de Chomsky. De esta manera, influyó en la lingüística computacional y en los sistemas expertos basados en sistemas de diálogos de pregunta y respuesta, con una base de datos primitiva, un motor de búsqueda y resolución de problemas mediante el lenguaje natural que faculta a las máquinas a comunicarse con las personas. Es más, en la actualidad, la IA tiene la capacidad de detectar la personalidad a través del lenguaje, crear un perfil y hasta saber si una persona se enfada fácilmente.

\section{Robótica}

El vocablo robótica fue acuñado por el escritor Isaac Asimov (1942), en su obra Runaround (Círculo vicioso, en español), para definir la disciplina científica que estudia los robots. Esta es, entonces, la ciencia que estudia el diseño y construcción de máquinas capaces de desempeñar las tareas del ser humano mediante procesos mecanizados y programados, que requiere los conocimientos de varias disciplinas como el álgebra, la informática, la electrónica, la mecánica, la física y la IA.

En dicho libro, el destacado escritor de ciencia ficción formuló las tres reglas fundamentales de la robótica, en los siguientes términos: 
Una, un robot no puede hacer daño a un ser humano, o, por medio de la inacción, permitir que un ser humano sea lesionado. [...] Dos -continuó Powell-, un robot debe obedecer las órdenes recibidas por los seres humanos excepto si estas órdenes entrasen en conflicto con la Primera Ley. [...] Y tres, un robot debe proteger su propia existencia en la medida en que esta protección no sea incompatible con la Primer o la Segunda Ley (Asimov, 1942, p. 13).

Posteriormente, en otro de sus libros -Robots e imperio-, Asimov (1985) estableció que

Hay una ley que es superior a la primera ley. «Un robot no puede lastimar a la humanidad o, por falta de acción, permitir que la humanidad sufra daños». La considero ahora la ley Cero de la Robótica. La primera ley debería decir: «Un robot no debe dañar a un ser humano, o permitir, por inacción, que el ser humano sufra algún daño, a menos que tal acción viole la ley Cero de la Robótica» (p. 254).

Estas leyes constituyen un verdadero código ético de la robótica, al poner como límite del accionar de la tecnología el daño a la humanidad y dar pautas de actuación en casos de dilemas éticos sobrevinientes. ${ }^{2}$

Dejando atrás las narrativas de ciencia ficción, entre las definiciones dadas, se puede mencionar que robot "es una máquina, provista de cierta complejidad tanto en sus componentes como en su diseño o en su comportamiento, y que manipula información acerca de su entorno para así interactuar con él" (García-P., 2018, p. 38). Barrio (2018a) afirma que es prudente referirse al robot strictu sensu al que define como "aquel objeto mecánico que capta el exterior, procesa lo que percibe, y a su vez, actúa positivamente sobre el mundo" (p. 70). Específicamente, la International Federation of Robotics (2018), en línea con la International Organization for Standardization ISO 8373:2012, Robots and robotic devices - Vocabulary, un robot industrial es "un manipulador multiusos,

2 Es de destacar la íntima asociación con la palabra robot, término inglés proveniente de la traducción del vocablo checo "robota", utilizado en una obra teatral de Karel Čapek, R.U.R. Robots Universales Rossum, estrenada en Praga en 1921. En español, este significa trabajo servil o esclavo, vale decir, una especie de esclavo artificial que hace todo lo que el humano no quiere o no puede hacer. 
reprogramable y controlado automáticamente, programable en tres o más ejes, que pueden estar fijos o móviles para uso en aplicaciones de automatización industrial" (p. 1).

Los robots coexisten en la sociedad del siglo XXI, sin embargo, ya en 1960 se utilizaron para tareas peligrosas o riesgosas como manejo de materiales tóxicos y radiactivos y cargar piezas en hornos y fundidoras. Algunas aplicaciones sencillas son las llamadas tres D en inglés: dark (oscuras), dirty (sucias) y dangerous (peligrosas), incluyendo tareas indeseables, pero necesarias, y también las tres $\mathrm{H}$ en inglés: hot (calientes), heavy (pesadas) y hazardous (riesgosas) (Kalpakjian \& Schmid, 2002).

Paulatinamente, se va ampliando la posibilidad de usos desde los tradicionales modelos de fabricación utilizados en la industria clásica, hasta el tránsito por las ciudades; por ejemplo, los automóviles autónomos, las aeronaves con comando remoto que sobrevuelan el espacio aéreo, los drones y los buques no tripulados que navegan por las aguas.

Además del uso industrial y comercial, los robots están reemplazando a los artefactos domésticos en las casas inteligentes, pueden llegar a zonas del espacio exterior antes vedadas al conocimiento humano y combatir en la guerra.

La pandemia de la COVID-19 evidenció la importancia de la colaboración de los robots en las más diversas tareas, que abarcan desde el control del distanciamiento social y la realización de actividades de limpieza, de entrega de domicilios y de asistencia sanitaria, entre otras (Jaimovich, 2020).

En la actualidad, hay variados criterios para clasificar a los robots conforme a su arquitectura, su aplicación, las generaciones (llegando hasta la cuarta y quinta), los niveles del lenguaje de programación y de control, y sus formas. Conforme esta última tipología, pueden ser antropomorfos o no (como se ejemplificó en la introducción).

Un desafío a sortear por los desarrolladores de los robots es la paradoja de Moravec, la cual consiste en que las máquinas son capaces de hacer cosas que son difíciles para los seres humanos, como jugar al ajedrez, pero incapaces de aprender habilidades psicomotrices o perceptivas que hasta un bebé posee. Conforme van avanzando y ampliandose las diferentes prestaciones de la IA y la robótica, tanto la comunidad internacional como algunos Estados individualmente comenzaron a intentar 
regular jurídicamente estas tecnologías disruptivas con el objetivo de dotar de un marco legal y ético a los fabricantes, científicos y usuarios. Si bien la regulación jurídica de estas tecnologías en el ámbito civil y comercial no es objeto de este trabajo, a continuación, se mencionarán las iniciativas más relevantes.

La Unión Europea se constituyó en un referente mundial en la elaboración de un marco jurídico integral, en el seno del Parlamento Europeo se dictó, el 16 de febrero de 2017, una resolución con recomendaciones a la Comisión para la elaboración de una normativa civil en materia de robótica: "Comunicaciones de la Comisión al Parlamento Europeo, al Consejo Europeo, al Consejo, al Comité Económico y Social Europeo y al Comité de las Regiones" sobre a) "Inteligencia artificial para Europa", 25 de abril de 2018, b) "Plan Coordinado sobre la Inteligencia Artificial", en diciembre de 2018, c) "Generar confianza en la inteligencia artificial centrada en el ser humano", 8 de abril de 2019 y d) la Resolución del Parlamento Europeo referida a la política industrial global europea en materia de inteligencia artificial y robótica, 12 de febrero de 2019.

A nivel estadual, se destacan la Korean Law on the Development and Distribution of Intelligent Robots de 2005 y la Intelligent Robots Development and Distribution Promotion Act de 2008, ambas de Corea del Sur, y la New Robot Strategy y la Robot Revolution Iniciative de 2015, de Japón. Emiratos Árabes Unidos es la única región del mundo que cuenta con un ministro de IA, pero todavía no ha sancionado una normativa específica.

\section{Sistemas de armas letales autónomas}

E1 25 de septiembre de 2018, el secretario general de las Naciones Unidas, Antonio Gutierres, en su discurso de apertura de los debates de la Asamblea General formuló una dura advertencia sobre el aumento de la militarización de la IA y en la cercana posibilidad de la creación de armas que seleccionen y ataquen por sí solas un objetivo sin el control humano (Naciones Unidas, 2018). Esta preocupación es compartida tanto por la mayoría de la comunidad científica y las organizaciones no gubernamentales, -entre ellas Human Rights Watch, International 
Human Rights Clinic y Pax-, como por varios Estados, entre ellos Argentina, Bolivia, Chile, Costa Rica, Cuba, Ecuador, Egipto, Ghana, la Santa Sede, México y Nicaragua.

Actualmente, tanto China como Estados Unidos están priorizando la inversión en IA, específicamente en el campo militar, lo que se podría traducir en una nueva carrera armamentística entre las dos grandes potencias, que compiten no solo en el plano económico, sino también en el tecnológico y militar.

En julio de 2017, dentro del plan Made in China 2025, el gigante asiático presentó su estrategia de IA con el objeto de mejorar la competitividad y proteger la seguridad nacional. Unos meses más tarde, el presidente de Rusia, Vladimir Putin, afirmó que aquel que se constituyera en el líder en IA gobernará el mundo. Frente a las precitadas declaraciones y el atraso tecnológico de Estado Unidos con respecto a sus competidores, el presupuesto del Departamento de Defensa destinado a IA militar y al aprendizaje automático aumentó, en el 2020, de 645000 millones a 833 millones de euros. Los proyectos abracan desde las tareas más rutinarias, por ejemplo, predecir el mantenimiento de los tanques y camiones, hasta tecnologías más avanzadas (Knight, 2019).

Frente a este nuevo escenario de incertidumbre internacional y de avances tecnológicos militares, y a los efectos del presente artículo, es necesario categorizar las armas según el tipo de control o participación de los seres humanos sobre sus acciones, es decir su grado de autonomía.

En primer lugar, se encuentran los sistemas en los que los individuos tienen control sobre ellas, vale decir que la máquina selecciona objetivos y utiliza la fuerza solo si la persona lo ordena. En segundo lugar están las que son controladas parcialmente por los seres humanos, lo que significa que tienen la posibilidad de seleccionar objetivos y llevar a cabo algún tipo de acción violenta, pero siempre bajo la supervisión de una persona que puede detener las acciones del arma y corregir las decisiones que no considere apropiadas. Por último, se encuentran las armas que no tienen ningún control humano sobre sus acciones, por lo tanto, no hay interacción con las personas ni se les pueden dar órdenes para detenerse (Sánchez Castro, 2016). Estas constituyen los sistemas de armas letales totalmente autónomas (LAWS, por sus siglas en inglés: lethal autonomous weapons systems), también denominados 
"robots asesinos", que despiertan un gran temor en miras a que, en un futuro, esos robots -en realidad algoritmos- puedan ocupar el lugar de los soldados seleccionando y atacando objetivos por sí mismos (Human Rights Watch, 2020).

\section{Concepto}

En la actualidad no se ha logrado un consenso general acerca de la definición de los LAWS. Entre las más difundidas se puede mencionar la adoptada por Human Rights Watch y por la International Human Rights Clinic del programa de Derechos Humanos de la Universidad de Harvard, que destacan que "son aquellas que tienen la capacidad de detectar, seleccionar y atacar objetivos, sin ningún tipo de intervención humana" (International Human Rights Clinic e Human Rights Watch, 2012, p. 2). En otras palabras, podrán decidir a quién atacar, haciendo uso de IA, lo que eliminaría cualquier tipo de intervención humana.

Para el Comité Internacional de la Cruz Roja, los LAWs son "aquellos que tienen autonomía en sus funciones críticas, vale decir que poseen la capacidad de seleccionar objetivos, detectarlos, identificarlos, rastrearlos y/o monitorearlos. Además, pueden atacarlos, usar la fuerza, neutralizarlos, hacerles daño o destruirlos; sin intervención humana" (International Committee of the Red Cross, 2016, p. 1).

Por su parte, la Campaña para Detener los Robots Asesinos -Campaign to Stop Killer Robots- (2013), una coalición internacional compuesta por organizaciones no gubernamentales, considera que estas armas tendrán la capacidad de seleccionar y disparar a objetivos por sí mismo sin ninguna intervención humana. Por lo tanto, el control humano sobre este tipo de máquinas es fundamental para asegurar la protección humanitaria y un control legal efectivo. Asimismo, el Departamento de Defensa de los Estados Unidos, en la Directiva 3000.09, del 12 de noviembre de 2012 las define como

un sistema de armas que, una vez activado, puede seleccionar y enfrentarse a objetivos sin la intervención de un operador humano. Esto incluye los sistemas de armas autónomos supervisados por humanos que están diseñados para permitir a los operadores anular el 
sistema automático, pero pueden seleccionar y atacar objetivos sin mayor intervención humana después de su activación (United States Department of Defense, 2012).

El documento de trabajo presentado, en el año 2017, por la delegación de los Países Bajos dentro del Grupo de Expertos Gubernamentales (GEG) en el contexto de la Convención de Ginebra de 1980 sobre prohibición o restricciones en el uso de ciertas armas convencionales que puedan ser consideradas excesivamente dañinas o que tengan efectos indiscriminados, diferencia entre las armas autónomas bajo control humano significativo de las totalmente autónomas. En las primeras, los sistemas no deciden un ataque individual sobre un objetivo específico, sino que desempeñan un papel prominente en a) la programación de las características de los objetivos que van a ser atacados; b) la selección de objetivo, del arma y la planificación de la ejecución (tiempo y espacio) y en una evaluación de los potenciales daños colaterales; c) la decisión de desplegar el arma, y d) la evaluación de daños en combate después del ataque, en la cual puede responsabilizarse a los oficiales al mando. Por el contrario, en los sistemas de armas totalmente autónomos, sin la posibilidad de un control humano, es un arma la que selecciona y ataca objetivos que cumplen unos criterios predefinidos y una vez lanzado el ataque, este no puede ser detenido por la intervención humana.

En la actualidad, más de 380 armas o sistemas robóticos semiautónomos fueron desarrollados en varios países, entre ellos China, Francia, Israel, Gran Bretaña, Rusia y Estados Unidos. Si bien, todavía no existen armas totalmente autónomas, se puede afirmar que en solo unos pocos años podrán ser utilizadas en los conflictos armados, fundamentalmente, por los rápidos avances en el desarrollo de la robótica y de la IA, así como por los importantes recursos financieros dedicados al campo militar en los países desarrollados, en especial por las dos potencias. En consecuencia, la sustitución de los soldados humanos por máquinas no parece ser un escenario muy lejano.

Sin embargo, es necesario aclarar que un sistema totalmente autónomo nunca se puede abstraer de algún tipo de intervención humana, ya que debe ser programado para respetar parámetros específicos $\mathrm{y}$, para ello, requiere de la participación de al menos un operador o un 
informático (Schmitt, 2013). En la actualidad muchos armamentos militares poseen altos niveles de automatización, son semiautomáticos, como por ejemplo los drones de guerra o vehículos no tripulados de combate aéreo (UCAV). Dichos sistemas están facultados para realizar tareas de forma automática: despegar, aterrizar y sobrevolar determinadas áreas por su cuenta sin necesitar ningún tipo de asistencia humana a lo largo de rutas indicadas por coordenadas GPS.

\section{Utilización de armamento militar semiautomático en el contexto militar}

Los vehículos aéreos no tripulados (VANT) fueron creados por un ingeniero nacido en Bagdad, Abraham E. Karem., quien se mudó a Israel justo después que se estableciera el Estado, en 1948. Durante la guerra de Yom Kippur, en 1973, Karem construyó su primer avión no tripulado consistente en un señuelo. Básicamente era un misil que podía controlarse con un joystick y que la Fuerza Aérea Israelí ${ }^{3}$ utilizó para activar y detectar los radares egipcios, para posteriormente destruirlos con misiles antiradiación disparados desde aviones de combate cercanos. Después de la guerra, Karem y su familia se mudaron a Los Ángeles, allí construyó un nuevo avión no tripulado, llamado Ámbar. Eventualmente, la compañía de Karem terminó siendo parte de General Atomics, donde desarrolló una generación posterior de Amber, llamada Gnat 750.

El punto de inflexión para Karem llegó, en 1993, cuando estalló una guerra étnica en la antigua Yugoslavia. Los combatientes llevaban ropa de civil y el gobierno de los Estados Unidos tenía dificultades para evaluar la situación sobre el terreno. El entonces director de la CIA, R. James Woolsey, recordó un viaje que había realizado a Israel donde había visto una nueva unidad de aviones no tripulados y contrató a Karem para su fabricación. En seis meses, el Gnat 750 estaba volando en misiones de reconocimiento sobre Bosnia y unos días después se

\footnotetext{
3 Para mayor información, véase: “Cómo Israel tomó un juguete y lo transformó en un arma de alta tecnología" (22 de marzo de 2019) Shalom. Recuperado de: https://www. shalom.cl/como-israel-tomo-un-juguete-y-lo-transformo-en-un-arma-de-alta-tecnologia/
} 
instaló una transmisión en vivo de los drones en la oficina de Woolsey. Allí pudieron monitorear el tránsito peatonal a través de un puente en Mostar, mientras se comunicaba con la estación terrestre a través de una forma temprana de software de chat.

El Pentágono le otorgó a General Atomics un contrato para desarrollar un avión más robusto pero el mayor cambio se produjo con la colocación de un enlace de comunicación por satélite en la aeronave. Así se creó el RQ-1 Predator (renombrado posteriormente como MQ-1) con posibilidad de portar dos misiles AGM-114 Hellfire. El Predator pasaría a ser famoso como el arma más letal de Estados Unidos en la guerra mundial contra el terrorismo, responsable de innumerables ataques en Yemen desde 2002, en Pakistán desde 2004 y en Somalia desde 2007. En junio de 2011, los Predators habían ayudado a la detención de casi 5000 indocumentados y 238 traficantes de drogas.

La primera misión importante del Predator fue el 3 de noviembre de 2002, en Yemen. Se trató del primer asesinato selectivo conocido en Estados Unidos utilizando el dron de la CIA, lanzado desde Camp Lemonnier, una base militar estadounidense en Djibouti. El Predator arrojó un misil que impactó contra un automóvil que circulaba por una carretera de la localidad de Marib, al este de Yemen. Entre los muertos se encontraban el líder de Al Qaeda, Qa'id Salim Sinan al Harithi, también conocido como Abu Mi y Abu Ahmad al Hijazi, ciudadano estadounidense naturalizado, también conocido como Kemal o Kamal Darwish, sospechoso de ser el reclutador de una célula de apoyo al terrorismo que había sido detenida en Búfalo, Nueva York.

Según los informes, los otros cuatro muertos pertenecían al ejército islámico de Adén-Abyan y fueron identificados como Salih Hussain Ali al Nunu o Zono (también conocido como Abu Humam), Awsan Ahmad al Tarihi (también conocido como Abu al Jarrah), Munir Ahmad Abdallah al Sauda (Abu Ubaidah) y Adil Nasir al Sauda (Abu Usamah, inicialmente identificado como al-Qia'gaa). Los seis nombres fueron revelados por el gobierno de Yemen tres semanas después del ataque. Una séptima persona se cree que pudo haber escapado. En un cable diplomático filtrado de 2004, el entonces embajador de Estados Unidos en Yemen dijo a una delegación de Amnistía Internacional que la acción 
se había tomado en plena cooperación con el Gobierno de la República de Yemen, en el marco de la lucha contra el terrorismo. ${ }^{4}$

La utilización de los drones en ataques militares selectivos produjo manifestaciones y acalorados debates desde el punto de vista del derecho internacional de los conflictos armados (DICA) tanto por parte de sus defensores señalando sus ventajas, como por sus detractores, se analizaron las consecuencias de las probables y posibles fallas durante su empleo con los resultantes "daños colaterales" a la población civil, sus pertenencias y sus hábitats.

Los drones tienen una lista innumerable de ventajas que los hacen preferibles a los aviones de combate tripulados: son más pequeños y livianos, cuestan menos y pueden sobrevolar los objetivos por más tiempo y flotar sobre ellos mientras el zumbido de sus motores se mezcla con el tráfico de la ciudad. Para operaciones militares, sirven a los propósitos de reconocimiento de zonas áreas y caminos, que permiten con bajo tiempo de preparación, acceder a espacios bajo control del enemigo con bajas probabilidades de detección y pérdidas de recursos materiales y de personal. En la actualidad y en operaciones de combate con armamento, es decir artillados, han facilitado la disminución de las bajas a un costo cero, y abarcan cada vez distancias mayores, con aparatos cada vez más sofisticados. Además, portan equipos de inteligencia de imágenes de alta resolución y emplean municiones guiadas, rasgos que los hacen más aptos que los aviones de combate tripulados, a la hora de realizar ataques de precisión, pues evitan la exposición de las tropas a las reacciones del enemigo $u$ oponente. Por las razones antedichas, constituyen armas perfectas para eliminar objetivos en movimiento, minimizan las bajas propias y maximizan las del enemigo.

Sin embargo, es dificultoso distinguir entre combatientes y no combatientes, cuando estos se entremezclan y tienen una apariencia similar. Sumado a ello, algunos líderes y militantes viven con sus familias y los errores de inteligencia que, en una guerra no se pueden desterrar

4 Para ampliar sobre la utilización de drones en la lucha de Estados Unidos contra el terrorismo, véase: “Yemen: Reported US Covert Actions 2001-2011". The Bureau of Investigative Journalism. Recuperado de: https://www.thebureauinvestigates.com/drone-war/data/yemenreported-us-covert-actions-2001-2011y BBC (November 5, 2003) News CIA “Killed al-Qaeda suspects" in Yemen". BBC News. http://news.bbc.co.uk/2/hi/2402479.stm 
por completo, tienen como consecuencia que los ataques con drones también provoquen la muerte de civiles, en algunos casos de ancianos, mujeres y niños. Uno de los ataques erróneos que atrajo mayor atención mediática se produjo el 2 de septiembre de 2012, cuando se disparó sobre una camioneta ocupada por catorce personas; entre los pasajeros muertos, había una mujer y dos niños (Jordán, 2013).

Por otro lado, preocupa el estrés psicológico y emocional que pueden sufrir sus operadores al causar destrucción y muerte a individuos vistos a grandes distancias como puntos en sus pantallas al dar click a un botón de sus computadoras, sin la certeza absoluta de su culpabilidad, salvo el simple hecho que se encuentran en lugares sospechosos.

Peter Bergen y Daniel Rothenberg (2014), desde una perspectiva interdisciplinaria integral sobre drones, cubren los debates más importantes sobre asesinatos selectivos y víctimas civiles, a la vez que presentan datos clave sobre el despliegue de dichas armas. En su libro, Drone Wars: Tranforming Conflict, Law, and Policy, señalan que los drones han llegado a simbolizar el nuevo carácter del conflicto moderno tanto en la diplomacia, como en la guerra. El dron ofrece una nueva forma de proyectar la fuerza letal, además de permitir una vigilancia continua

Para la diplomacia, el control de armas y la simple curiosidad sobre lo que está sucediendo dentro de un país son una poderosa consecuencia de la tecnología. Siria, por ejemplo, no puede confiar en que no se detecten productos químicos en movimiento. Advierten que, en los últimos quince años y a medida que se fueron desarrollado otros tipos de guerra como la cibernética e incluso la nuclear, también ha aumentado la importancia de un buen sistema inteligente para la vigilancia. Además, las innovaciones tecnológicas a futuro serán mucho más efectivas y los drones comenzarán a ser accesibles para el público en general, lo que los convierte en una potencial amenaza a la propia seguridad. En cuanto a la precisión del ataque, el Body Count de Paquistán estimó que entre el 75 y el $80 \%$ de los muertos por drones son civiles. En el año 2010, el periódico en inglés de más tirada en Paquistán, Dawn, afirmaba que en promedio los drones habían matado a 140 civiles por cada militante (Bergen \& Rothenberg, 2014). Durante el periodo 2004-2010, los 114 ataques con drones documentados en el noroeste de Pakistán han acabado con la vida de entre 830 y 1210 individuos, de los cuales 
entre 550 y 850 fueron descritos como militantes en crónicas de prensa fiables. Por ello, el verdadero índice de mortalidad civil desde 2004 es de aproximadamente 32\% (Bergen \& Tiedemann, 2010).

A la supuesta eficacia de los drones a nivel militar se deben contraponer los efectos que crean en la población civil receptora de los ataques. Así, se argumenta que esta práctica fomenta el sentimiento antiamericano no solo en los países que los reciben, como Pakistán o Yemen, sino en toda la región. El riesgo de los ataques aéreos es que estos, a causa de los errores y muerte de no combatientes, envíen el mensaje justamente contrario: son ineficientes.

El debate académico sobre las ventajas y desventajas del uso de los VANT en conflictos simétricos y asimétricos sigue en pie, pues aunque se puede percibir que ayudan a mermar las fuerzas del enemigo, no determinan la victoria en las guerras. En consecuencia, se presentan como un medio de disuasión. En efecto, sus defensores afirman que han sido estratégicamente productivos, ya que han logrado disminuir la cantidad de líderes yihadistas radicales en el Medio Oriente y en el Asia Meridional. Debido a los ataques precisos por los drones, se han imposibilitado sus reuniones, sus programas y sus actividades en los campos de entrenamiento, y se ha anulado prácticamente su infraestructura logística. No obstante, sus detractores afirman que, en lugar de la esperada intimidación y disuasión, se desencadena más bien un mayor desafío, deseos de venganza, resentimiento, furor y odio contra la fuente de sus males, es decir el Occidente en general y Estados Unidos en particular.

Más allá de los pro y contra, hay una realidad incontrastable: cada vez se fabrican más drones y su uso trasciende el estrictamente militar. Se emplean tanto en el ámbito civil, como estrictamente militar, que en muchos casos son coincidentes.

En 2007, General Atomics puso en servicio el MQ-9 Reaper, una versión más grande y eficaz del Predator, que muchos comparan con el CH-5 Rainbow, de China. Además de los misiles Hellfire, cuenta con bombas guiadas por láser GBU-12 y por GPS GBU-38, JDAM. El Reaper es capaz de volar durante catorce horas con un máximo de carga y puede completar el ciclo de ataque: encontrar, fijar, seguir, marcar, atacar y valorar los daños. Aunque su uso ha estado mayormente relacionado 
con los misiles de guerra, también ha sido útil en operaciones de inteligencia y vigilancia, reconocimiento y rescate. Actualmente, la Fuerza Aérea de los Estados Unidos cuenta con una flota de 93 de estas naves.

Un riesgo real es que estos también pueden ser utilizados por terroristas. En efecto, en 2019, rebeldes hutíes de Yemen se atribuyeron el ataque múltiple a las instalaciones petrolíferas saudíes utilizando sus propios drones. ${ }^{5}$

En enero del 2020 se produjo un incidente que reabrió la polémica sobre los aviones no tripulados letales. Los medios aseguraron que la muerte de Qassem Soleimani, quien era el militar más poderoso del régimen iraní y el número dos de las milicias chiítas iraquíes, Abu Mahdi al Muhandis fue producida por un dron de vigilancia y combate MQ-9 Reaper en una carretera cercana al aeropuerto de la capital iraquí de Bagdad. El pentágono confirmó que la orden la había impartido Donald Trump, pero no identificó el arma. El "asesino de los cielos", como llaman los medios a dicho dron, cuenta con un sistema de apuntado multiespectral que le permite descubrir y designar objetivos mediante sensores láser e infrarrojos, así como a través del uso de diversas cámaras que, además, permiten ver su actividad en directo desde cualquier rincón del planeta. ${ }^{6}$

Inmediatamente se conoció la noticia, se reinstaló el debate entre los grupos de defensa de los derechos humanos y los grupos antiterroristas. También se sumaron a la discusión los vendedores de armas, así como los defensores de la segunda enmienda de la constitución norteamericana o el derecho constitucional de portar armas para legítima protección y defensa. La mayoría de los estadounidenses cree que la guerra con drones ayuda a mantenerlos a salvo. Según datos de Pew Research de mayo de 2015, el 58\% de los estadounidenses aprueba el uso de aviones no tripulados en ataques contra presuntos terroristas en países extranjeros. También aprueban la política de la "guerra de

5 Para conocer más detalles del ataque véase: ¿Quién puede estar detrás de los ataques con drones en las refinerías saudíes? (19 de septiembre de 2019) La Vanguardia. Recuperado de: https://www.lavanguardia.com/internacional/20190917/47411234331/ataque-dronesrefinerias-petroleo-arabia-saudi-quien-puede-estar-detras.html

6 Vid:"Cómo funciona el MQ-9 Reaper, el drone que EEUU utiliza en sus operativos" (3 de enero de 2020) Infobae. Recuperado de: https://www.infobae.com/america/mundo/2020/01/04/como-funciona-el-mq-9-reaper-el-drone-que-eeuu-utiliza-en-sus-operativos/ 
los drones" ya que el terrorismo representa una amenaza mortal que no respeta a seres humanos inocentes ni personas indefensas. Parten del principio de la guerra justa y transforman el concepto de legítima defensa en legítima defensa preventiva (Vélez, 2020).

En Francia, se puede mencionar el Neuron, un avión invisible de combate de diez metros no tripulado que puede volar de forma autónoma por más de tres horas en misiones de detección, localización y reconocimiento autónomo de objetivos terrestres. Cuenta con funciones totalmente automatizadas de ataque, ajuste de objetivos y comunicación entre sistemas. Otro ejemplo es Harpy, de fabricación israelí, que es un misil de permanencia en vuelo o loitering (merodeo) de 2.1 metros. Está equipado con una ojiva con quince kilogramos de explosivos y puede permanecer en vuelo en modo merodeo por hasta nueve horas, en busca de señales de radares enemigos. Sus finalidades son detectar, atacar y destruir los radares enemigos automáticamente (Pax, 2015). Actualmente se diseñó Harop, la evolución de Harpy, también denominado Harpy 2.

A lo largo de la zona desmilitarizada en la frontera con la República Popular Democrática de Corea, esta ha desplegado varios robots militares SGR-A1 encargados de la vigilancia, que pueden disparar automáticamente ante la presencia del enemigo, pero no contra las personas que tienen las manos en alto (Sychev, 2018).

El tanque de combate Armata T-14 de Rusia puede disparar de forma autónoma y se espera que sea totalmente autónomo en un futuro próximo. El Sea Hunter de la Armada de Estados Unidos, un buque autónomo de guerra de cuatro metros de eslora, se convirtió en el primer buque sin tripulación. Diseñado para buscar submarinos enemigos, puede funcionar sin contacto con un operador humano por dos o tres meses seguidos. También está el avión estadounidense X-47B, totalmente autónomo y controlado remotamente por un humano (Bradley, 2019). Además, Estados Unidos está desarrollando proyectos como el ATLAS (Advanced Targeting and Lethality Automated System), que incorpora la IA a los tanques para identificar y atacar objetivos al menos el triple de rápido que con el actual proceso manual (BBC News Mundo, 2019).

Actualmente, existen formas de sistemas mixtos: humanos con capacidades aumentadas o reforzadas por máquinas. Esta interconexión 
alcanza, con la robotización, un alto grado de sofisticación y poder: el swarming ${ }^{7}$ o actuación en enjambre. Estados Unidos está desarrollando varios proyectos para operar de esta forma: el programa Gremlins de pequeños UAV (unmanned air vehicle, vehículos aéreos no tripulados), lanzados desde otras aeronaves y dirigidos por medio de IA; el LOCUST, un vehículo aéreo no tripulado con tecnología de enjambre, con el objeto de saturar las defensas aéreas enemigas con un gran número de blancos, y el Perdix, un prototipo de VANT desarrollado por el prestigioso MIT, ya probado, que consiste en un aparato del tamaño de la mano, protegido en un envoltorio, que se conecta con más de cien aparatos que conforman el enjambre y ejecuta las órdenes recibidas (Gómez de Águeda, 2019).

No se puede dejar de mencionar la nueva estrategia norteamericana de seguridad nacional denominada Third Offset Strategy, en español tercer contrapeso o tercera estrategia de compensación, anunciada por el Secretario de Defensa, Chuck Hagel, el 15 de noviembre de 2014, que apuesta por tres tecnologías disruptivas: la IA, los metadatos y la nube. Actualmente, la situación para los Estados Unidos se ha vuelto muy complicada, pues tras el tiempo perdido en las guerras de Irak o Afganistán, sin posibilidad de maniobra estratégica, ha visto cómo sus rivales han pasado a la ofensiva, acercándose a áreas clave y cuestionando su papel como primera potencia global.

Dicha estrategia parte de la base de solucionar cuatro grandes problemas operativos: a) la vulnerabilidad de las instalaciones norteamericanas en el extranjero, susceptibles de caer bajo los ataques de saturación enemigos, b) los rivales se han dotado de medios cada vez más potentes, c) la mejora de las defensas antiaéreas, que hacen cada

7 El swarming, enjambre en español, es un tipo de estrategia aplicable en todo tipo de conflictos, ya sea militares, convencionales, ciberguerra, guerra en red, etc. Consiste en atacar y confundir al enemigo a través de la convergencia de ataques de muchas unidades autónomas o semiautónomas sobre un objetivo y bajo diferentes formas. Aspectos importantes en esta estrategia son la movilidad, el reagrupamiento, la comunicación, y coordinación/sincronización de sus actividades. El enemigo parece estar en todas partes, pero sólo se ve en un número reducido, lo cual incita a la víctima a subestimar o sobreestimar el tamaño del oponente. Las teorías de swarming se derivan de la observación de la naturaleza, en donde comunidades biológicas como los lobos, las abejas y las hormigas, actúan eficazmente coordinadas. Véase: Gloffka R., A. (2011) "Swarming: Una mirada a la guerra desde las dos caras del dios Janus" Military Review, 42-48. 
vez más vulnerables los aparatos de cuarta generación y d) las capacidades antisatélite (ASAT) chinas y rusas que provocan que los satélites norteamericanos sean susceptibles de ser atacados tanto por medios físicos - misiles antisatélite- como cibernéticos.

Por ello, Estados Unidos apuesta por aquellas tecnologías que hoy día cuentan con ventaja significativa sobre sus potenciales rivales, fundamentalmente China. Dichas tecnologías se relacionan con los siguientes campos:

a) Operaciones no tripuladas: incluye los sistemas aéreos, terrestres o marinos tanto de superficie, como de inmersión con sistemas no tripulados y cada vez más autónomos.

b) Operaciones navales y aéreas a grandes distancias: mediante bases expedicionarias flotantes o a través de aviones cisterna no tripulados que permitan aumentar significativamente el radio de acción de los aparatos de las fuerzas de Estados Unidos sin depender de aliados poco fiables.

c) Operaciones no-observables: comprende las tecnologías furtivas que van mucho más allá de la "invisibilidad" al radar. Aspectos como la composición del material, la pintura, las emisiones infrarrojas y muchos otros factores complican la invisibilidad a niveles insospechados.

d) Guerra submarina: es otro de los campos dominado por Estados Unidos, pero China está construyendo submarinos no tripulados que serían capaces de llevar a cabo ataques de estilo kamikaze contra buques enemigos.

e) Ingeniería e integración de sistemas: es la clave de todo el edificio militar estadounidense. Consiste en un sistema de sistemas, centrado en nuevos niveles de cooperación interarmas dentro de cada ejército e interejércitos dentro del conjunto de sus fuerzas armadas y permita un mayor control sobre el campo de batalla.

En resumen, la tercer estrategia de compensación está orientada, precisamente, a compensar los avances chinos y hace hincapié en prescindir de los costosos despliegues actuales, reducir al mínimo la exposición de combatientes humanos por medio del empleo de sistemas aéreos, 
navales y terrestres no tripulados controlados a distancia e incluso autónomos y, por encima de todo, golpear en cualquier lugar y momento a partir del desarrollo de una red global de observación y ataque.

Dicha red posibilitaría el ataque mediante armas inteligentes como misiles de crucero o vehículos aéreos no tripulados allí donde fuera necesario y sin depender de costosas bases fijas ni de satélites, cada vez más vulnerables. Se prevé un conflicto extremadamente tecnificado con un conjunto de unidades de combate formadas por redes de máquinas y seres humanos destinadas a actuar en un régimen de colaboración para sincronizar diferentes tipos de operaciones: multitud de drones actuando en enjambre, liderados por un único humano situado a miles de kilómetros de distancia obturarán por saturación las defensas antiaéreas enemigas o atacarán objetivos independientes con una precisión sorprendente. En la guerra del futuro, los robots autónomos cumplirían el rol de la infantería tradicional, reconociendo y limpiando las zonas en disputa, programados para distinguir amigos de enemigos y para reducir al máximo las bajas de no combatientes.

Asimismo, misiles hipersónicos podrían ser lanzados desde la seguridad del territorio nacional a prácticamente cualquier parte del mundo en cuestión de minutos y monitorizados en tiempo real, mientras que entre cada humano, buque y avión comparten absolutamente toda la información que cada uno recoge y el propio sistema se encarga, monitorizado por humanos o no, de decidir cómo utilizarla de la forma más ventajosa (Villanueva López, 2018).

En el centro de esta estrategia de compensación se encuentra la red global de observación y ataque que se prevé estará consolidada en el 2030. Se identificaron como prioridades la implementación de medidas de reducción de la dependencia norteamericana a los satélites por su alta vulnerabilidad y su reemplazo por medidas alternativas para la navegación de precisión, como desplegar drones estratégicos de observación, reconocimiento o adquisición de objetivos y desarrollar un sistema de comunicación complementario a las comunicaciones satelitales (Colom, 2015).

La Administración Trump ha continuado el desarrollo de la Administración Obama. Así, la Estrategia de Defensa Nacional de 2018 recoge la IA entre el conjunto de tecnologías que están cambiando el 
carácter de la guerra junto con los metadatos, la computación avanzada, la robótica y la energía dirigida, entre otras. Lo significativo de esta estrategia es que subraya la competencia con China y Rusia, a quienes considera como los rivales y competidores estratégicos más importantes.

\section{Marco normativo}

En materia de conflictos armados, se aplican las cuatro convenciones de Ginebra de 1949 y sus protocolos adicionales, que codificaron parte del denominado derecho de guerra, que a partir de ese momento comenzó a llamarse derecho humanitario.

E1 I Convenio de Ginebra de 1949 protege, durante la guerra, a los heridos y enfermos de las fuerzas armadas en tierra, así como al personal médico y religioso, quienes deberán ser tratados de forma respetuosa. El segundo convenio es similar, pero está referido a las fuerzas armadas en el mar. El tercero, por su parte, protege a los prisioneros de guerra y responsabiliza a las potencias que los capturaron, imponiendo el tratamiento humanitario y respeto a la dignidad humana, independientemente de las personas naturales bajo cuya supervisión se encuentren. El cuarto se ocupa de la población civil bajo la ocupación militar del enemigo. Específicamente, con referencia a la ayuda humanitaria que deban recibir los habitantes en las áreas militarmente ocupadas, presenta una detallada normativa. Frente a numerosas lagunas de las que adolecían los precitados convenios, se dictaron dos protocolos adicionales, en 1977. El primero refuerza "la protección a las víctimas de los conflictos internacionales", y el segundo su protección "en los conflictos no internacionales".

Ambos ponen coto y determinan la manera en que se realizan las acciones bélicas. A los efectos del presente trabajo, resulta relevante la prohibición establecida en el artículo 35 del primer protocolo sobre la utilización de cierto armamento, así como proyectiles y formas de combate que causen males y sufrimientos innecesarios. Este obliga a los combatientes a proteger y siempre diferenciar entre combatientes militares y civiles en virtud de la denominada "cláusula Martens", en alusión al jurisconsulto de nacionalidad rusa que la planteó; tanto las personas civiles como los combatientes estarán protegidos por los 
principios de humanidad, los mandatos de la conciencia pública y los usos y costumbres de las naciones civilizadas (Barboza, 2008).

Como dichos instrumentos internacionales no pueden predecir todos los escenarios ni las invenciones en las tácticas ni en las armas militares, en todas las convenciones y sus protocolos se destaca la aplicación de los principios generales en cualquier circunstancia. Esos principios generales que rigen las controversias bélicas son el de discriminación, el de proporcionalidad, el de humanidad y el de precaución.

El primero se fundamenta en dos importantes diferenciaciones. En primer lugar, distingue entre población civil y combatientes, y, en segundo, entre bienes civiles y objetivos militares. La alocución "objetivo militar", en una interpretación amplia, incluye a bienes, personas, ciudades y localidades pasibles de acciones bélicas durante la contienda. Con frecuencia se diferencia entre los objetivos no militares y los militares, ya que no se permite el ejercicio de hostilidades contra los bienes no militares ni la población civil. En este protocolo los objetivos militares se reducen a "aquellos objetos que, por su naturaleza, ubicación o finalidad contribuyan a la acción militar y cuya destrucción total o parcial, ofrezca una ventaja militar" (artículo 52, inciso 2). Si bien tal caracterización de objetivo militar puede resultar ambigua, precisar los bienes civiles no pasibles de ataque imposibilita que se extienda la noción de objetivo militar.

En consecuencia, dicho protocolo otorga una tutela concreta a los bienes culturales (siempre que no se usen con un fin militar), a determinados bienes civiles básicos y vitales de la población como las tierras agrícolas, la ganadería, los cultivos, los depósitos y provisión de agua potable y los canales para el riego, así como a las represas, diques y plantas térmicas nucleares para la generación de energía eléctrica. Con respecto a la población civil, prohíbe cualquier tipo de acción bélica contra dicha población en conjunto y contra los individuos no militares, así como los actos o intimidaciones en el uso de la fuerza para generar terror en la población civil. Los individuos que participen activamente en las acciones bélicas no se encuentran bajo el amparo de dicha protección, mientras dure su intervención. Por el principio de precaución en el ataque, se deben tomar todos los posibles recaudos en pos de impedir, o por lo menos, reducir a un mínimo, la cantidad de heridos 
y fallecimientos entre los individuos civiles, así como los detrimentos a bienes civiles, que incidentalmente se pudieran ocasionar.

Estos principios se complementan con el de proporcionalidad. En virtud del mismo se prohíben las acciones bélicas cuyos perjuicios, así como la cantidad de víctimas en la población civil, sobrepasen claramente la ventaja militar concreta que pueda conseguirse. Especial atención merece la primera sección del Título III (métodos y medios de guerra) en donde se reiteran los principios generales y claramente expresa que los medios y métodos no son ilimitados, veda la utilización de todo tipo de armamentos que produzcan "males superfluos o sufrimientos innecesarios". Dicha prohibición surge de las consideraciones humanitarias y las necesidades militares desde la perspectiva del equilibrio de armamentos entre los Estados. Además, si un Estado contratante desarrolla, adquiere o adopta una nueva arma o nuevos métodos de guerra, tiene la obligación de determinar si su empleo está prohibido por cualquier otra norma de derecho internacional aplicable a dicho Estado. ${ }^{8}$

La práctica internacional ha seguido la tendencia de combinar la prohibición de categorías amplias o genéricas de armas con la de armas específicas, dejando importantes cuestiones sin resolver. En virtud de tales circunstancias, la conferencia celebrada en Ginebra en 1979 y 1980 aprobó, el 10 de octubre de 1980, la Convención sobre prohibiciones o restricciones del empleo de ciertas armas convencionales que puedan considerarse excesivamente nocivas o de efectos indiscriminados, seguida de tres protocolos: Protocolo I sobre fragmentos no localizables; Protocolo II sobre prohibiciones o restricciones del empleo de minas, armas trampa y otros artefactos, enmendado en 1996, y Protocolo III sobre prohibiciones o restricciones del empleo de armas incendiarias.

8 Con respecto a todo este plexo jurídico, la Corte Constitucional Colombiana, en su Sentencia C-225/95, dictaminó que forman parte de ius cogens (Hurtado Granada, 2017). Conforme la Convención de Viena sobre Derecho de los Tratados de 1969, artículo 53. Tratados que están en oposición con una norma imperativa de derecho internacional general (jus cogens): "Para los efectos de la presente Convención, una norma imperativa de derecho internacional general es una norma aceptada y reconocida por la comunidad internacional de Estados en su conjunto como norma que no admite acuerdo en contrario y que solo puede ser modificada por una norma ulterior de derecho internacional general que tenga el mismo carácter. Se trata de una norma aceptada y reconocida por todos los Estados que no admite acuerdo en contrario y solo puede ser modificada por una norma ulterior del Derecho Internacional". 
En 1995, la Conferencia de examen de la Convención de 1980 aprobó un nuevo protocolo -el cuarto- sobre armas láser cegadoras y en 2003 un quinto sobre los restos de guerra explosivos y minas distintas de las antipersonas (Diez de Velasco, 2007).

Toda esta normativa humanitaria se aplica a la utilización de las armas semiautomáticas. Sin embargo, no se presenta el mismo consenso internacional en cuanto a la suficiencia de dicho marco jurídico y ético para el caso del desarrollo de las LAWS.

A continuación, se desarrollarán los principales argumentos a favor y en contra de la posible utilización de las LAWs y de la consecuente celebración de un tratado específico preventivo que prohíba su uso.

\section{Luces y sombras sobre la regulación específica de las LAWS}

Sus defensores, entre ellos Estados Unidos, aseveran varias ventajas. La primera consiste en que ofrecen una mayor protección de las fuerzas armadas propias, ya que no son los soldados los que exponen directamente sus vidas. Si bien se diferencia entre víctimas civiles y militares, estos últimos no son elementos fungibles privados de dignidad humana. La implantación de sistemas robóticos en el campo de batalla evita cualquier baja humana ya sea civil o militar. Es mejor que los robots luchen entre ellos y que los humanos no intervengan. Además, un robot no puede ser asesinado, lastimado ni ser tomado como rehén. La segunda afirma que estos sistemas incrementan los factores de protección con que cuenten las fuerzas todavía presentes en el frente. Las actividades de exploración, defensa avanzada y otras altamente arriesgadas se externalizan en sistemas teledirigidos o autónomos. ${ }^{9}$ Como tercera, derivada de la anterior, al reducirse las bajas propias, los que desatan los conflictos armados, pueden alcanzar mayor rédito político ya que

9 Este argumento fue esgrimido por la Delegación de Estados Unidos en el Grupo de Trabajo de las Altas Partes Contratantes de sobre ciertas armas convencionales, en mayo de 2018. El documento se puede consultar en: Group of Governmental Experts of the High Contracting Parties to the Convention on Prohibitions or Restrictions on the Use of Certain Conventional Weapons Which May Be Deemed to Be Excessively Injurious or to Have Indiscriminate Effects. "Humanitarian benefits of emerging technologies in the area of lethal autonomous weapon systems Submitted by the United States of America". CCW/GGE.1/2018/ WP.4. 28 march 2018. 
la población pierde interés por el desarrollo del conflicto armado y no ofrece sustanciales resistencias ante la guerra. En cuarto lugar, pueden mantenerse en el teatro de operaciones mucho más tiempo que las personas con costos muchísimo menores. Los robots son mucho más eficientes que los seres humanos, los objetivos son elegidos y eliminados con mayor precisión, minimizando los daños colaterales. En contraste con los sistemas existentes controlados remotamente, como los drones, las LAWS no requieren de una constante conexión ni comunicación permanente.

Esos sistemas no necesariamente serían menos propensos a ser hackeables, pero evitarían latencias técnicas y los tiempos de reacción son mucho más rápidos que los de los humanos. En quinto lugar, permiten que las operaciones se realicen en áreas apartadas, inhóspitas, zonas contaminadas u ocupadas por terroristas o por enemigos. Si los soldados fueran enviados a esos lugares se los estaría sentenciando a la muerte (Dahlmann, 2019).Como ultuma ventaja se encuentra la ausencia del factor emocional. Por un lado, se enfatiza que estas armas no conocen el miedo o el pánico, lo que las transforma en más objetivas en el cumplimiento de las misiones, ya que, frente a la inexistencia de las pasiones humanas, no actúan matizadas por el odio o la sed de venganza. Como ventaja adicional, Sassoli (2014) menciona que, al ser algoritmos, pueden ser programadas para registrar la información necesaria que permita reconstruir los sucesos para las investigaciones penales.

Sus detractores, en cambio, aseveran que las LAWS difícilmente podrían llegar a cumplir con los principios de derecho internacional humanitario. Con respecto al principio de distinción, si bien la tecnología avanza en el desarrollo de capacidades sensoriales y de procesamiento, distinguir entre un combatiente activo y un civil, un soldado herido o que se ha entregado requiere funciones mucho más complejas: implica interpretar el significado de pistas sutiles para medir la intención humana, como el tono de voz, las expresiones faciales o el lenguaje corporal, en un contexto específico, los humanos poseen la capacidad única de identificarse con otros seres humanos.

Al analizar el principio de proporcionalidad concluyen que el obrar de las máquinas se tornaría más riesgoso, ya que requiere el delicado equilibrio de dos factores: el daño civil y la ventaja militar. La 
proporcionalidad no solo tiene lugar al desarrollar un plan de batalla general, sino también durante las operaciones militares in situ. La ventaja militar debe determinarse caso por caso y resulta imposible programar por adelantado el número infinito de contingencias que podrían surgir en el momento del ataque. Por otro lado, la decisión de desplegar un arma totalmente autónoma no es semejante a la decisión de atacar. En el momento de tomar dicha decisión, tal arma estaría fuera del control humano. El estándar del comandante militar razonable sería difícil de emular en una máquina, máxime cuando la decisión de atacar se toma en circunstancias imprevistas o cambiantes.

Esta problemática obliga a analizar el concepto de razonabilidad. El mismo presenta un vínculo importante con la razón humana y con consideraciones éticas y morales. Los juicios sobre si un ataque en particular es proporcional deben ser una cuestión de sentido común y buena fe, que no puede ser comprendido por un robot. Un tema muy espinoso consiste en deslindar la responsabilidad penal por actos criminales y civiles por la reparación del daño causado, ya que no se puede responsabilizar a los robots, además, estos serían incapaces de internalizar la culpa. En los casos de armas totalmente autónomas, sería muy difícil justificar la atribución de responsabilidad directa a los individuos por algún tipo de accionar de dichas máquinas contrario al derecho internacional humanitario. Estas, por su naturaleza, estarían facultadas para obrar de forma autónoma y, por consiguiente, se visualiza el riesgo que ataquen de manera impensable e indistintamente a la población civil. No es jurídicamente posible responsabilizar directamente al comandante o al programador por las acciones específicas del robot salvo que implementaran un arma a sabiendas y con un propósito delictivo, como asesinar a cualquier persona sin distinción, o si lo diseñaran para cometer actos criminales. En síntesis, el sistema de responsabilidad penal diseñado para los humanos sería insuficiente para las LAWS, nadie podría ser considerado criminalmente responsable.

Otro aspecto a tener en cuenta, señalan sus opositores, es en cuanto a la aplicación de la "cláusula Martens", un robot autónomo no podría obrar bajo los preceptos humanitarios ni los mandatos de la conciencia pública, debido a que carecen de emociones humanas, incluida la compasión. Justamente, dicha estipulación fue invocada para justificar 
la prohibición preventiva de las armas láser cegadoras que tengan como finalidad total o parcial producir ceguera en forma definitiva.

Otro de los temores más peligrosos consiste en que, una vez desarrolladas, estas armas podrían utilizarse en la lucha contra los delitos comunes internos, las manifestaciones contra los poderes públicos y cualquier tipo de conmoción interior, lesionando los derechos humanos reconocidos internacionalmente. Los humanos, en general, conservan sentimientos nobles como la empatía y la misericordia y son renuentes a matar a un vencido. Por tanto, dichas emociones funcionan como un impedimento para asesinar inocentes. Como estas máquinas carecen de los sentimientos y emociones humanas, no tendrían la capacidad de comprender el significado de la rendición de los combatientes enemigos o si presentan lesiones. Todo ello evitaría muertes innecesarias. La decisión de la vida y la muerte librada a las máquinas, resulta ética y moralmente repudiable.

Los humanos, al estar dotados de razón e intelecto, poseen un juicio prudencial con capacidad de interpretar el espíritu legislativo. Ningún robot, por mucha información que pueda procesar, posee este juicio. Las determinaciones sobre quien vive o muere en los enfrentamientos bélicos pueden necesitar de sentimientos humanos, de los que los robots no son portadores. Un riesgo adicional a la carencia de sentimientos y conciencia consiste en que las máquinas totalmente autónomas se podrían transformar en peligrosos instrumentos en manos de dictadores para doblegar y dominar a su propio pueblo. La historia demuestra que los ejércitos más duros pueden rebelarse contra la opresión en defensa de su gente o si se les ordena cometer crímenes de lesa humanidad.

Sumado a esto, si bien dichas armas, al sustituir a los soldados humanos en batalla, podrían disminuir las lesiones y muertes militares, las semiautónomas no necesitan una presencia humana en el campo. Sus operadores pueden mantenerse seguros en una ubicación remota (Human Rights Watch \& Human Rights Clinic, 2020). Otro aspecto relevante y que preocupa a los altos mandos militares, es la posibilidad de que este tipo de armas sea hackeada por una persona humana $\mathrm{u}$ otra IA. Se pueden modificar en forma imperceptible los datos recibidos por los sensores del robot para manipular, desconcertar y confundir a la IA: "Los misiles guiados por inteligencia artificial podrían ser cegados 
por los datos antagónicos y tal vez incluso redirigidos hacia objetivos amistosos" (Knight, 2019).

En virtud de lo anteriormente expuesto, un grupo de expertos científicos e investigadores -entre ellos, Stuart Russell, Elon Musk, Stephen Hawking, Noam Chomsky, Peter Norving y Mustafa Suleyman- publicaron una carta en el Future of Life Institute solicitándole a la Organización de Naciones Unidas que prohíba el desarrollo y uso de armas mortíferas controladas por software autónomo porque estas podrían convertirse en armas terroríficas de déspotas en contra de poblaciones inocentes.

Cuando un ser humano está en una situación de conflicto, toma decisiones en las que intervienen, entre otras, sus actitudes morales, sentimientos y emociones. La observación directa del sufrimiento de los demás produce un efecto disuasivo en los soldados, aun cuando, entre los militares profesionales, la compasión y la sensibilidad terminan por desaparecer (Russell et al., 2015). En igual sentido Amnistía Internacional expidió la Campaign to Stop Killer Robots, que representa a setenta organizaciones en treinta países, en particular PAX, Human Rights Watch, Article 36, el Comité Internacional de la Cruz Roja y los Relatores Especiales de Naciones Unidas sobre las Ejecuciones Extrajudiciales -Christof Heyns-y sobre los Derechos a la Libertad de Reunión Pacífica y de Asociación, la Santa Sede y otros líderes religiosos, en pos de lograr que se prohíban las LAWS.

En consecuencia, expertos, organizaciones no gubernamentales y diplomáticos, a partir del 2014, se reunieron ocho veces en Ginebra en el marco de la Convención sobre ciertas armas convencionales para analizar las cuestiones legales, éticas, operativas y tecnológicas relativas a los armamentos autónomos, sin obtener resultados satisfactorios. En la actualidad la mayoría de países promueven vigorosamente la adopción de un tratado de prohibición preventivo al sistema de armas totalmente autónomo, así como la necesidad de mantener algún tipo de control humano significativo como esencial para estigmatizar la eliminación del control humano de los sistemas de armas. Sin embargo, Japón y el Reino Unido anunciaron que no poseen sistemas de armas totalmente autónomos y no tienen intención de desarrollarlos. Para Estados Unidos, Reino Unido, Australia, Rusia e Israel, las actuales normas sobre conflictos 
pueden ser suficientes para regular la situación de las armas autónomas en combate (Gayle, 2019).

En septiembre de 2019, en la Asamblea General de alto nivel de las Naciones Unidas, Francia y Alemania, junto con Canadá, México, Chile, Singapur y Gana, organizaron el evento Alianza por el Multilateralismo. Esta busca maximizar los apoyos a iniciativas temáticas concretas, entre ellas once principios sobre los LAWS como uno de los seis temas políticamente relevantes que requieren una respuesta multilateral urgente. Según estos principios rectores, el derecho internacional humanitario se aplica a estos sistemas; la responsabilidad en la decisión de hacer uso de ellos siempre se debe atribuir a una persona humana, y en la fase de diseño, los Estados deben examinar la licitud de las armas nuevas que desarrollan o adquieren (Ministerio para Europa y Francia de Asuntos Exteriores, 2019).

En consonancia, en noviembre de 2019, la Campaign to Stop Killer Robots elaboró un documento sobre los elementos clave para un tratado sobre armas totalmente autónomas. En primer lugar, enfatiza la prohibición de este tipo de armas por parte del nuevo derecho internacional y el control humano significativo. Este último debe estar presente tanto en la toma de decisiones, como en los componentes tecnológicos y operacionales. En la toma de decisiones porque proporcionan a los seres humanos la información y la capacidad de tomar decisiones sobre si el uso de la fuerza cumple con las normas jurídicas y los principios éticos. Además, propone tres tipos de obligaciones para los Estados: a) general de mantener el control humano significativo sobre la utilización de la fuerza; b) negativas o la prohibición de los sistemas de armamentos que seleccionan y atacan objetivos sin un control humano significativo -abarcaría también aquellas que son problemáticas por su naturaleza, por ejemplo, los que se basan en ciertos tipos de datos para representar a personas o categorías de personas sobre indicadores discriminatorios relacionados con la edad, el género u otras identidades sociales-, y c) positivas específicas para asegurar un control humano significativo (Dochert, 2019).

Finalmente, el Parlamento Europeo instó al desarrollo urgente de una postura en común y legalmente obligatoria para tratar las cuestiones jurídicas y éticas con relación a la rendición de cuentas, el significativo 
contralor humano, la supervisión y la aplicación del derecho humanitario internacional, las tácticas militares y los derechos humanos reconocidos internacionalmente. La resolución del parlamento sobre los sistemas de armas autónomos, dictada el 12 de septiembre de 2018, afirma que este tipo de armamentos tienen la aptitud de modificar los términos de la guerra y de conducir una carrera o guerra armamentista incontrolable e inaudita. Específicamente y con referencia a la selección y ataque de objetivos, presenta importantes dilemas éticos y legales sobre el significativo control humano. Como los robots no son humanos, carecen de la facultad para la toma de decisiones en las que estén involucrados los principios del derecho humanitario de proporcionalidad, distinción y precaución. Este contiene, además, algunas definiciones: por "sistemas armamentísticos autónomos letales" entiende que es un sistema de armas que no posee un control humano significativo con referencia a la selección y ataque de objetivos individuales, excluyendo los sistemas teledirigidos, con control a distancia y demás sistemas no autónomos. Destaca la necesidad de vedar la producción y desarrollo de los sistemas que no tengan control humano en las funciones fundamentales, como seleccionar y atacar objetivos, y resalta que la Unión no cuenta con armas letales autónomas entre los armamentos que actualmente utiliza (Parlamento Europeo, 2018).

Un tema que preocupa tanto en el ámbito gubernamental como científico-tecnológico consiste en las fallas de las que pueden ser objeto estas máquinas, debido a algún código escrito incorrectamente o por un ciberataque. Tanto el control, como la intervención y la vigilancia humana son fundamentales en el momento y oportunidad de tomar decisiones mortales, porque los responsables de definir la vida y la muerte de las personas siguen siendo los seres humanos.

\section{La guerra del futuro. La guerra centrada en redes}

Con base en la estrategia de compensación norteamericana, se puede afirmar que surgió una nueva forma de resolver los conflictos armados basada en la red global de observación y ataque. Autores como Nieto y Mateo (2014) la denominan guerra de la información 
(informatión warfare) porque el empleo del ciberespacio, el espectro electromagnético y la información sobre el oponente se ha tornado vital para la transmisión de información y órdenes desde y hacia los elementos ejecutores de las acciones militares.

En este punto revisten particular importancia los sistemas de comunicación a través de los vehículos autónomos estratosféricos, ya que dicha altura da un radio de cobertura para los sensores tan importante como el de un satélite de baja cota. Estos sistemas también podrían ser utilizados como repetidores de comunicaciones y alternativas a los satélites. Por ello se requiere el dominio del ciberespacio, las nuevas tecnologías de la información, la nanotecnología y el acceso a sistemas de telecomunicaciones robustos y seguros en todos los dominios.

Sin embargo, los actores estatales no poseen el monopolio de la IA y la globalización de la información constituye un importante obstáculo a vencer. Son las grandes multinacionales tecnológicas las que están detrás de las disrupciones tecnológicas, a favor o en contra de los intereses de esos Estados, por lo que no se debe menospreciar su capacidad de interacción público-privada en la búsqueda de una posición hegemónica en el mercado global. A causa de esto, los sistemas cibernéticos militares pueden ser de dos tipos: abiertos o cerrados. Los primeros son las redes accesibles para cualquier usuario que desee ingresar, con clave de identificación, encriptamiento y con herramientas de protección comerciales. Es muy importante compartir la información y las medidas de rendimiento y conectividad. La vulnerabilidad de dichos sistemas es su dependencia, tanto de productos como en servicios, de las capacidades civiles en el espacio cibernético. Debido a la debilidad de los sistemas abiertos que dependen de los sistemas comerciales, es que las fuerzas militares se esfuerzan por desarrollar sus propios sistemas para reducirlas.

En cambio, las redes militares cerradas tienen acceso solamente a los nodos autorizados y están aisladas de las redes abiertas. Las principales medidas de rendimiento de las redes cerradas son seguridad, disponibilidad y certeza en la información que se trasmite. Son vulnerables a infecciones o programas maliciosos introducidos vía una USB. A pesar de que las redes en el ciberespacio son interdependientes, las cerradas son aisladas. El aislamiento en el ciberespacio existe a través 
de protocolos, firewalls, encriptación y separación física de otras redes. Por ejemplo, existen redes clasificadas, como la denominada us Armed Forces Secure Internet Protocol Router network (SIPRnet) que no están conectadas a Internet en todo momento, pero que pueden hacerlo y conectarse a través de portales seguros.

Si bien pueden usar conectividad comercial, en el caso de sistemas cerrados, el personal militar es el que controla el acceso, los nodos y el tráfico, por ejemplo, para Estados Unidos, el Secret Internet Protocol Router Network and Secure Telephone Units. En Argentina existen dos canales del satélite ARSAT de uso exclusivo militar, pero esta información es clasificada, por lo que es contradictoria según las fuentes.

Siguiendo en esta línea, para los analistas y planificadores chinos, la fuente de la eficacia militar de Estados Unidos proviene de la integración de sistemas de información militar y civil, que también es un centro de gravedad vulnerable, pues si el adversario fuese capaz de desbaratar dichas redes y acceder a la información, podría dejar a las fuerzas de combate estadounidenses y a sus comandantes en un estado de parálisis (Vergara \& Trama, 2017).

Por eso, el líder chino, Xi Jinping, en el año 2018, anunció que él mismo presidiría la Administración del Ciberespacio de China a fin de promover la cibersoberanía como principio organizador de la gobernanza de Internet, en oposición directa al apoyo de Estados Unidos de una Internet global y abierta. En otras palabras, el presidente de China quiere pasar de una Internet basada en una red de informática mundial (World Wide Web) y un modelo distribuido de gobernanza de la web en el que participan organismos técnicos, el sector privado, la sociedad civil y los gobiernos, a un mundo interconectado a través de redes nacionales, con un control gubernamental justificado por los derechos soberanos de los Estados. ${ }^{10}$

Es más, las comunicaciones móviles de banda ancha son el santo grial de las tecnologías de defensa. El mundo militar quiere adquirir la capacidad de comunicarse que proporcionan las últimas tecnologías

10 Véase: Guerra Mundial Web: cómo China promueve una Internet menos libre y con mayor control estatal. (22 de septiembre de 2018). Infobae. https://www.infobae.com/america/ mundo/2018/09/22/guerra-mundial-web-como-china-promueve-una-internet-menos-libre-ycon-mayor-control-estatal/ 
civiles. Las viejas radios tácticas no proporcionan las funcionalidades demandadas. Los comandantes de las operaciones deben contar con la misma tecnología que impulsa redes celulares comerciales de alta velocidad para poder enviar imágenes, video y realizar un seguimiento de la ubicación de su unidad en tiempo real.

En un futuro, las unidades militares comenzarán a beneficiarse de tecnologías importadas de las redes $4 \mathrm{G}$ y serán capaces de utilizar radio software inteligentes de salto de frecuencia y aprovechar el espectro no utilizado. La seguridad de las comunicaciones es uno de los principales obstáculos para la adopción de dispositivos tipo smartphones, aunque se está trabajando en nuevas maneras de proteger sus datos. Todo parece indicar que en un futuro no tan lejano versiones militares de estos aparatos desempeñarán un papel importante en el combate (Ramos Villena, 2014). Esto apunta a algunas de las razones de la lucha entre Estados Unidos y China por el 5G. Dicha tecnología cuenta con una velocidad de descarga de 20 gigas por segundo y cada celda puede soportar hasta 100 conexiones simultáneas y una mayor eficiencia energética (McLoughlin, 2019).

De estas redes depende el despliegue de la llamada internet de las cosas, que conecta miles de millones de objetos y máquinas difundiendo la información en todos los ámbitos de la vida con extraordinaria rapidez y de forma global. La gran preocupación norteamericana no es solo económica sino militar. Aquí, Huawei tiene, según la opinión casi unánime de los expertos, una clara hegemonía que va incrementándose. Quien domine los estándares de comunicación en el inicio de esta nueva tecnología de redes domina su futuro, porque el 6G ya está en la fase de prototipos en Huawei. El profundo significado de esta batalla es que ha empezado la guerra por el nuevo poder mundial. Estados Unidos estaba relativamente tranquilo en su hegemonía, porque estaba seguro de su superioridad tecnológica que se traducía en superioridad económica y militar. La superioridad económica ya ha desaparecido y la tecnológica empieza a desvanecerse en sectores clave como el 5G (Castells, 2019).

Otro de los riesgos es que, muchas de las tecnologías utilizadas en el campo militar, pasan a ser de uso civil. El ejemplo más ilustrativo es el de los VANT, cuya aplicación es de las más variadadas: desde la medición 
de áreas y superficies, reconocimientos de zonas y áreas de difícil accesibilidad, control de incendios forestales, hasta para posicionamiento para tareas de rescate, búsqueda y salvamento, donde las capacidades de transmisión de la información en tiempo real son vitales.

El hecho que al vehículo se le pueda incluir casi cualquier complemento -incluyendo el armamento siempre que las características físicas y técnicas lo permitan - hace que la línea entre la aplicación civil y militar sea muy borrosa. La transformación de un dron civil en uno de militar es completamente factible, incluso en cuanto a los drones armados. A esta característica, inherente de los drones, se la conoce como doble uso (Rodríguez et al., 2019).

En 2015, un empleado que supuestamente trabajaba para una agencia de inteligencia estadounidense mostró lo fácil que era infiltrarse en un edificio de alta seguridad. Con un dron DJI Phantom sobrevoló accidentalmente por encima del jardín de la Casa Blanca sin ser detectado por el radar ya que este estaba calibrado para amenazas más grandes como aviones y misiles (Shear \& Schmidt, 2015).

Los drones y el software libre para su uso son accesibles al público en general, lo que los convierte en un verdadero riesgo que pasa de estar controlado por las fuerzas militares a manos de cualquier ciudadano para su seguridad privada. Los civiles generalmente están equipados con dispositivos que logran realizar capturas de imágenes, vídeos y grabación de audio, algunos vienen integrados con cámaras infrarrojas e incluso con sensores térmicos y pueden llegar a tener cuarenta horas de autonomía y su utilización es cada vez más común. Para el período 2013-2020, la consultora Teal Group estimó en 89 mil millones de dólares el mercado mundial de drones civiles y militares. En muchos casos con riesgo de vida, por ejemplo, un hombre de Pensilvania usó un dron para lanzar explosivos sobre la casa de su exnovia.

La utilización de los drones por parte de los particulares está preocupando a las autoridades, ya que están disponibles y se pueden comprar tanto en línea como en tiendas físicas. Por lo tanto, una empresa de seguridad aeroespacial de Utah, Fortem Technologies, ha hecho un dron que puede controlar otros drones. El DroneHunter identifica automáticamente al dron enemigo, le dispara una red a 80 millas por hora y lo arrastra hasta un lugar seguro (Bisset, 2018). Además, las empresas 
privadas han creado mecanismos de IA para labores de vigilancia, algunos de ellos con sistemas de inmovilización personal o dispositivos para hacer entregas de un punto a otro abriendo la posibilidad de entrar o lanzar explosivos caseros.

\section{Conclusión}

En el presente trabajo se conceptualizaron determinadas tecnologías disruptivas como la robótica y la inteligencia artificial, destacando sus diferencias, y que, si bien están estrechamente relacionadas, no son sinónimos. En especial se abordó la problemática de la aplicación de la inteligencia artificial a la robótica en el contexto militar.

Aun cuando los sistemas de LAws hasta la fecha no se han implementado en ataques militares, muchos prototipos son ensayados en laboratorios, lo que produce la necesidad de plantear si el actual marco jurídico de los derechos humanos reconocidos internacionalmente y el derecho internacional humanitario resulta suficiente y adecuado para su regulación o si es imprescindible dotar de un nuevo marco jurídico y ético, que aborde cuestiones específicas derivadas de la utilización de tales armamentos autónomos en los conflictos militares.

A ese respecto se analizaron las opiniones tanto en contra como a favor de su regulación a través de un nuevo tratado que prohíba preventivamente su utilización en cualquier conflicto armado, ya sea interno como internacional. Entre las ventajas acerca de la utilización de este tipo de sistemas de armas, sus defensores destacan la reducción de bajas humanas en el campo de batalla, la imposibilidad de toma de rehenes y la ausencia del factor emocional. En realidad, los robots desconocen el miedo, el odio y la sed de venganza, sentimientos propios de los seres humanos. Además, favorecen las actividades exploratorias en zonas inhóspitas, altamente riesgosas, contaminadas, ocupadas por terroristas y permiten la reconstrucción objetiva de los hechos para dilucidar responsabilidades penales, en especial en los delitos de lesa humanidad.

Por otro lado, los impulsores del dictado de un tratado que prohíba preventivamente su implementación en los conflictos armados aseguran 
que difícilmente se pueda cumplir con los principios del derecho humanitario. Un robot no posee empatía ni sentimientos de compasión ni las emociones ni los principios de humanidad. No poseen el juicio prudencial para decidir sobre la vida y la muerte de las personas. En el campo de batalla, resulta complejo observar los principios de proporcionalidad, razonabilidad, distinción entre personas y objetivos civiles y militares o un soldado herido o rendido y pueden ser hackeadas, manipuladas y cegadas por otra IA o por otro ser humano. Concluyen que teniendo en cuenta la fuerte inversión realizada por las superpotencias en la temática como los prototipos y ensayos existentes y los riesgos que conllevaría su utilización, la misma debe prohibirse de manera preventiva antes de que sea demasiado tarde cambiar de rumbo. Además, ya existe un antecedente de prohibición preventiva de determinado armamento: las armas láser cegadoras.

La línea argumentativa permite concluir que el derecho se debe anticipar a los hechos antes de que estos sean irreversibles ya que son temas que involucran la dignidad humana, la vida y la muerte. Pero, aún frente a la posibilidad del dictado de un tratado que las prohibiera preventivamente, la problemática no estaría zanjada. Por el principio de soberanía estatal, los tratados son vinculantes y obligatorios solo para los Estados que hayan dado el consentimiento en obligarse y, al parecer ni Estados Unidos ni Inglaterra ni China estarían dispuestos a ceder en este ámbito. Es más, en el hipotético caso que todos los Estados se obligaran por un instrumento internacional, o aún, considerándolo como derecho consuetudinario universal, persistiría el conflicto en caso que algún país miembro lo violentara. Morton Kaplan (1962), profesor emérito de ciencias políticas y especialista en relaciones internacionales en la Universidad de Chicago, definió el derecho internacional como "un sistema político sin fuerza legal". Lo que se plantea es la efectividad de la sanción frente al incumplimiento de una obligación internacional, ya que no existe un organismo dotado del poder de policía, la que va a depender del poder político y económico que el Estado infractor detente en la comunidad internacional.

En consecuencia, el debate está comenzando y no presenta una única solución como el dictado de un tratado preventivo y prohibitivo, sino que debe ir acompañado de un proceso participativo de los Estados, la 
industria, los programadores y desarrolladores de IA, las organizaciones sin fines de lucro y las instituciones académicas y científicas. Todos ellos deben adoptar un marco ético para el desarrollo de la IA y la robótica para el bien, centrada en el ser humano, que se beneficie de las ventajas de estas tecnologías, en cuanto a estrategia militar y disminución de bajas. A su vez, teniendo en cuenta los riesgos que pueden ocasionar, se deberá restringir su uso, comprometiéndose a respetar los principios de dignidad humana, control significativo, sostenibilidad, justicia, equidad, estado de derecho y rendición de cuentas. Específicamente es imprescindible mantener el control humano significativo, que implica la responsabilidad de una persona natural y la verificabilidad de sus decisiones y consecuencias. No hay dudas de que si las estrategias de los futuros combates se basaran en sistemas de armas y robots inteligentes, se debe consensuar en un marco jurídico y ético otorgando la última decisión en el uso de la fuerza letal al ser humano.

Por otro lado, no se puede obviar el auge que los aviones no tripulados están teniendo en la sociedad civil. Los particulares pueden adquirir drones para diferentes usos desde recreación, hasta vigilancia y seguridad personal. Incluso, se les pueden incorporar explosivos con el peligro que eso implica. En este último caso, y mientras se mantenga dentro de espacio aéreo de un Estado, su regulación es de incumbencia del derecho interno y no del derecho internacional. No obstante, es conveniente que dichas regulaciones sean uniformes en los diferentes países.

\section{Referencias}

Álvarez González, C. F. (217). "Análisis de la estrutura y organización de los Sistemas Autónomos de Armas Letales (LAWS) a partir de la lectura de Arnold Pacey" Eikasia Revista de Filosofía, 74, 9-47.

Arkin, R. (2014). Governing Lethal Behavior in Autonomous Robots. CRC Press Taylor \& Francis Group.

Asimov, I. (1942). Círculo vicioso. http://inteligenciaeducativa.net/descargas/ runaround.pdf

Asimov, I (1985). Robots e imperio. Titivillus. 
Barboza, J. (2008). Derecho internacional público. Zavalía.

Barrio, A. M. (Dir.). (2018a). Derecho de los robots. Wolters Kluwer.

Barrio, A. M. (2018b). Robótica, inteligencia artificial y derecho. ARI 103/2018. https://docplayer.es/94116118-Robotica-inteligencia-artificial-y-derecho. html

BвC (November 5, 2003). News CIA "Killed al-Qaeda suspects" in Yemen". BBC News. http://news.bbc.co.uk/2/hi/2402479.stm

Bergen, P., E Rothenberg, D. (2014). Drone wars: Transforming conflict, law, and policy. Cambridge University Press.

Bergen, P., \& Tiedemann, K. (abril 23, 2010). The year of the drone: An analysis of US drone strikes in Pakistan 2004-2010. Foreign Policy. https:// foreignpolicy.com/2010/04/23/the-year-of-the-drone/

Bisset, J. (septiembre 22, 2018). Los drones asesinos son caros, mortales y están disponibles en tu tienda más cercana. C|Net. https://www.cnet.com/ es/noticias/drones-asesinos/

Bradley, S. (abril 2, 2019). Armas polémicas. Robots asesinos: ¿hay que prohibirlos? SWI. Swissinfo. https://www.swissinfo.ch/spa/politica/armaspolémicas_robots-asesinos---hay-que-prohibirlos-/44867422

Brynjolfsson, E., E McAfee, A. (2014). The second machine age. Work, progress, and prosperity in a time of brilliant technologies. W. W. Norton E Company.

Cáceres, N. E. (2006). Constructivismo jurídico e inteligencia artificial en el proyecto Conacyt-IIJ-CCADET-TSJT. Revista El Siete. Revista Jurídica Estudiantil Departamento de Derecho Universidad de Sonora, 2(7), 2-16.

Campaign to Stop Killer Robots. (2013). Our first year of campaigning. https:// www.stopkillerrobots.org/2013/12/first-year-of-campaigning/?lang=es

Castells, M. (mayo 25, 2019). Guerra tecnológica. La Vanguardia. https://www. lavanguardia.com/opinion/20190525/462440941108/guerra-tecnologica. html

Colom, C. (2015). Rumsfeld revisted: La tercera estrategia de compensación estadounidense. Revista UNISCI (38), 69-88.

Comisión Europea. (2018). Comunicación de la Comisión al Parlamento Europeo, al Comité Económico y Social Europeo y al Comité de las Regiones: Inteligencia Artificial para Europa. COM(2018) 237 final. 25 de abril de 2018. Bruselas.

Cómo funciona el MQ-9 Reaper, el drone que EEUU utiliza en sus operativos. (enero 3, 2020). Infobae. https://www.infobae.com/america/ mundo/2020/01/04/como-funciona-el-mq-9-reaper-el-drone-que-eeuuutiliza-en-sus-operativos/ 
Cómo Israel tomó un juguete y lo transformó en un arma de alta tecnología. (marzo 22, 2019). Shalom. https://www.shalom.cl/como-israel-tomo-unjuguete-y-lo-transformo-en-un-arma-de-alta-tecnologia/

Dahlmann, A. (enero 18, 2019). Towards a regulation of autonomous weapons - A task for the EU? European Leadership Network. https://www. europeanleadershipnetwork.org/commentary/towards-a-regulation-ofautonomous-weapons-a-task-for-the-eu/

Diez de Velasco. M. (2007). Instituciones de derecho internacional público. Tecnos. Chomsky, N. (1957). Estructuras sintácticas. Siglo Xx Editores.

Docherty, B. (2019). Elementos clave de un tratado sobre armas totalmente autónomas. Campaign to Stop Killer Robots.

Francia, Ministerio para Europa y de Asuntos Exteriores. (2019). Once principios sobre los sistemas de armas autónomos letales. https://www.diplomatie.gouv.fr/ es/politica-exterior/francia-en-naciones-unidas/alianza-por-el-multilateralismo/article/once-principios-sobre-los-sistemas-de-armas-autonomos-letales

Gayle, D. (marzo 29, 2019). UK, US and Russia among those opposing killer robot ban. The Guardian. https://www.theguardian.com/science/2019/ mar/29/uk-us-russia-opposing-killer-robot-ban-un-ai

García, P. C. J. (2018). ¿Qué es un robot? En M. Barrio Andrés (Dir.), Derecho de los Robots. Wolters Kluwer.

Gloffka, R. A. (2011). Swarming: Una mirada a la guerra desde las dos caras del dios Janus. Military Review, 42-48.

Gómez de Águeda, A. (2019). La inteligencia artificial en el campo de batalla. En A. Gómez de Águeda \& J. Molino Martínez (Coords.), Usos militares de la inteligencia artificial, la automatización y la robótica (127-144). Instituto Español de Estudios Estratégicos.

Group of Governmental Experts of the High Contracting Parties to the Convention on Prohibitions or Restrictions on the Use of Certain Conventional Weapons Which May Be Deemed to Be Excessively Injurious or to Have Indiscriminate Effects. "Examination of various dimensions of emerging technologies in the area of lethal autonomous weapons systems, in the context of the objectives and purposes of the Convention. Submitted by the Netherlands" CCW/GGE.1/2017/WP.2. 9 October 2017.

Group of Governmental Experts of the High Contracting Parties to the Convention on Prohibitions or Restrictions on the Use of Certain Conventional Weapons Which May Be Deemed to Be Excessively Injurious or to Have Indiscriminate Effects. "Humanitarian benefits of emerging technologies in 
the area of lethal autonomous weapon systems Submitted by the United States of America". CCW/GGE.1/2018/WP.4. 28 march 2018.

Guerra Mundial Web: cómo China promueve una Internet menos libre y con mayor control estatal (septiembre 22, 2018). Infobae. https://www. infobae.com/america/mundo/2018/09/22/guerra-mundial-web-comochina-promueve-una-internet-menos-libre-y-con-mayor-control-estatal/

Heyns, C. (2013). "Report of the Special Rapporteur on extrajudicial, summary or arbitrary executions, Christof Heyns" Human Rights Council. General Assembly. United Nations. A/HCR/23/47. https://www.ohchr. org/Documents/HRBodies/HRCouncil/RegularSession/Session23/AHRC-23-47_en.pdf

Human Rights Watch. (2020). World report 2020: Ante la amenaza de los robots asesinos, crecen las demandas para que los humanos continúen en control del uso de la fuerza. https://www.hrw.org/es/world-report/2020/countrychapters/337416

Human Rights Watch \& Human Rights Clinic. (2020). Construyendo el caso. Los peligros de los robots asesinos y la necesidad de una prohibición Preventiva. Human Rights Watch.

Hurtado, G. M. I. (2017). Los límites del DIH a las armas autónomas. Revista Científica General José María Córdova, 15(20), 85-100. http://doi. org/10.21830/19006586.176

International Committee of the Red Cross. (2016). Views of the International Committee of the Red Cross (ICRC) on autonomous weapon system. International Committee of the Red Cross.

International Federation of Robotics. (2018). The impact of Robots on Productivity, Employment and Jobs. International Federation of Robotics.

International Human Rights Clinic \& Human Rights Watch. (2012). Losing humanity. The case against killer robots. Human Rights Watch

Jaimovich, D. (junio 14, 2020). El uso de robots y otras formas de inteligencia artificial en tiempos de coronavirus. Infobae. https://www.infobae.com/ america/tecno/2020/06/01/el-uso-de-robots-y-otras-formas-de-inteligencia-artificial-en-tiempos-de-coronavirus/

Jordán. J. (2013). La campaña de ataques con drones en Yemen. Revista del Instituto Español de Estudios Estratégicos (1), 37-59.

Kalpakjian, S. E Schmid, S. (2002). Manufactura, ingeniería y tecnología. Pearson Educación.

Kaplan, M. (1962). System and process in international politics. Wiley. 
Knight, W. (2019). La paradoja de la IA militar: un arma peligrosa que nadie debe obviar. MIT Technology Review. https://www.technologyreview. es/s/11563/la-paradoja-de-la-ia-militar-un-arma-peligrosa-que-nadie-debeobviar

La advertencia sobre los "robots asesinos", la nueva carrera armamentística entre EE.UU. y China (mayo 10, 2019). BBC News Mundo. https://www.bbc. com/mundo/noticias-48234592

Martínez Quirante, R. E Rodríguez Álvarez, J. (2018). Inteligencia Artificial y Armas Letales Autónomas. Un Nuevo Reto para naciones Unidas. Trea Ensayos.

Martínez, V. J. R., López, L. A, Srebrenica, B., E Fernández, A. N. (2019). Robótica, armas y derecho internacional. Editorial Tirant lo Blanch.

McCarthy, J. (2007). What is artificial intelligence. Universidad de Stanford. Sección Basic Questions. http://www-formal.stanford.edu/jmc/whatisai/ node1.htmll el 08.02.2020

McLoughlin, M. (junio 2, 2019). La verdadera historia tras la guerra del 5G (y el veto a Huawei): todo lo que debes saber. El Confidencial. https://www. elconfidencial.com/tecnologia/2019-06-02/huawei-5g-nokia-ericcsonlucha-mundial_2043234/

Naciones Unidas. (septiembre 25, 2018). La ONU alerta del peligro de los "robots asesinos" ante los líderes mundiales. El Nuevo Herald. https://www. elnuevoherald.com/noticias/mundo/article218987845.html

Nieto, R., \& Mateo, E. (2014). La aplicación del concepto inteligencia, vigilancia y reconocimiento (ISR) en espacios no tradicionales. En Escuela de Altos Estudios de la Defensa Documentos de Defensa y Seguridad 61: El impacto de las nuevas tecnologías y las formas de hacer la guerra en el diseño de las Fuerzas Armadas (pp. 153-206). Ministerio de Defensa.

Paniagua, E. (2019). Future trend forum. Inteligencia artificial. Fundación Innovación Bankinter.

Parlamento Europeo. (2018). Resolución del Parlamento Europeo, de 12 de septiembre de 2018, sobre los sistemas armamentísticos autónomos (2018/2752(RSP)). Diario Oficial de la Unión Europea. C 433/86 - C 433/88. 23.12.2019.

Pax. (2015). Robots asesinos ¿Qué son y por qué resultan preocupantes? Pax.

Pérez, L. A. (1996). Sistemas expertos jurídicos: premisas para un balance. En L. Peña, J. de Lorenzo Martínez, \& J. Echeverría Ezponda (Coords.), Calculemos... Matemáticas y libertad (pp. 273-300). Trotta.

¿Quién puede estar detrás de los ataques con drones en las refinerías saudíes? (septiembre 19, 2019). La Vanguardia. https://www.lavanguardia.com/ 
internacional/20190917/47411234331/ataque-drones-refinerias-petroleoarabia-saudi-quien-puede-estar-detras.html

Ramos Villena, C. (2014). El impacto de las nuevas tecnologías y las formas de hacer la guerra en el diseño de las Fuerzas Armadas del futuro. En Escuela de Altos Estudios de la Defensa, Documentos de Defensa y Seguridad 61: El impacto de las nuevas tecnologías y las formas de hacer la guerra en el diseño de las Fuerzas Armadas (pp. 13-57). Ministerio de Defensa.

Riquelme, R. (febrero 3, 2020). Conoce a los robots con inteligencia artificial. El Economista. https://www.eleconomista.com.mx/tecnologia/robots-coninteligencia-artificial-20200131-0081.html

Rodríguez, J., Mojal, X., Font, T., E Brunet, P. (2019). Nuevas armas contra la ética y las personas. Centre Delàs d'Estudis per la Pau.

Russell et al. (2015). Autonomous weapons: An open letter from AI E robotics researchers. The Future Life Institute. https://futureoflife.org/open-letterautonomous-weapons/?cn-reloaded $=1$

Sánchez, C. A. M. (2016). Robots asesinos. Campaign to Stop Killer Robots. https://www.stopkillerrobots.org/wp-content/uploads/2016/12/Robotsasesinos-2.pdf

Sassoli, M. (2014). Autonomous weapons and international humanitarian law: Advantages, open technical questions and legal issues to be clarified. International Law Studies, (90), 308-340.

Schmitt, M. (2013). Autonomous weapon systems and international humanitarian law: A reply to the critics. Hardware Law School National Security Journal. https://harvardnsj.org/wp-content/uploads/sites/13/2013/02/ Schmitt-Autonomous-Weapon-Systems-and-IHL-Final.pdf

Searle, J. (1980). Minds, brains, and programs. Behavioral and Brain Science, 3(3), 417-457.

Sharkey, N. (2012). "The evitability of autonomous war". International Review of Red Cross, 9 (886), 787-799

Shear, M., E Schmidt, M. (enero 27, 2015). White house drone crash described as a U.S. worker's drunken lark. The New York Times. https://www.nytimes. com/2015/01/28/us/white-house-drone.html

Sychev, V. (2018). La amenaza de los robots asesinos. El Correo de la Unesco. Inteligencia Artificial. Promesas y Amenazas, (3), 25-28.

United States, Department of Defense. (noviembre 21, 2012). Directive 3000.09: Autonomy in Weapon Systems. https://www.hsdl.org/?view G did=726163

Villanueva, L. C. D. (julio 16, 2018). Third offset strategy. ¿Preludio de una revolución militar? Ejércitos. Revista Independiente sobre Defensa, Armamento 
y Fuerzas Armadas. https://www.revistaejercitos.com/2018/07/16/thirdoffset-strategy/

Vélez, E. (enero 9, 2020). El ataque de EEUU con el dron que mató al general Suleimani reabre una polémica mundial. Alnavio. https://alnavio.com/ noticia/20178/actualidad/el-ataque-de-eeuu-con-el-dron-que-mato-algeneral-suleimani-reabre-una-polemica-mundial.html

Vergara, E., \& Trama, G. (2017). Operaciones militares cibernéticas: planeamiento y ejecución en el nivel operacional. Escuela Superior de Guerra Conjunta de las Fuerzas Armadas.

Walsh, T. (2020). "Killer Robots. La inteligencia artificial y las armas autónomas" Revista IDEES. https://revistaidees.cat/es/killer-robots/

Yemen: Reported us Covert Actions 2001-2011. The Bureau of Investigative Journalism. https://www.thebureauinvestigates.com/drone-war/data/ yemen-reported-us-covert-actions-2001-2011 